UC - NRLF कB l6 056

$1+1$

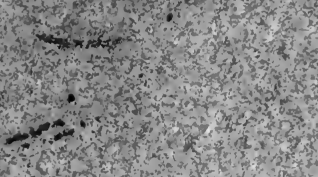

00 


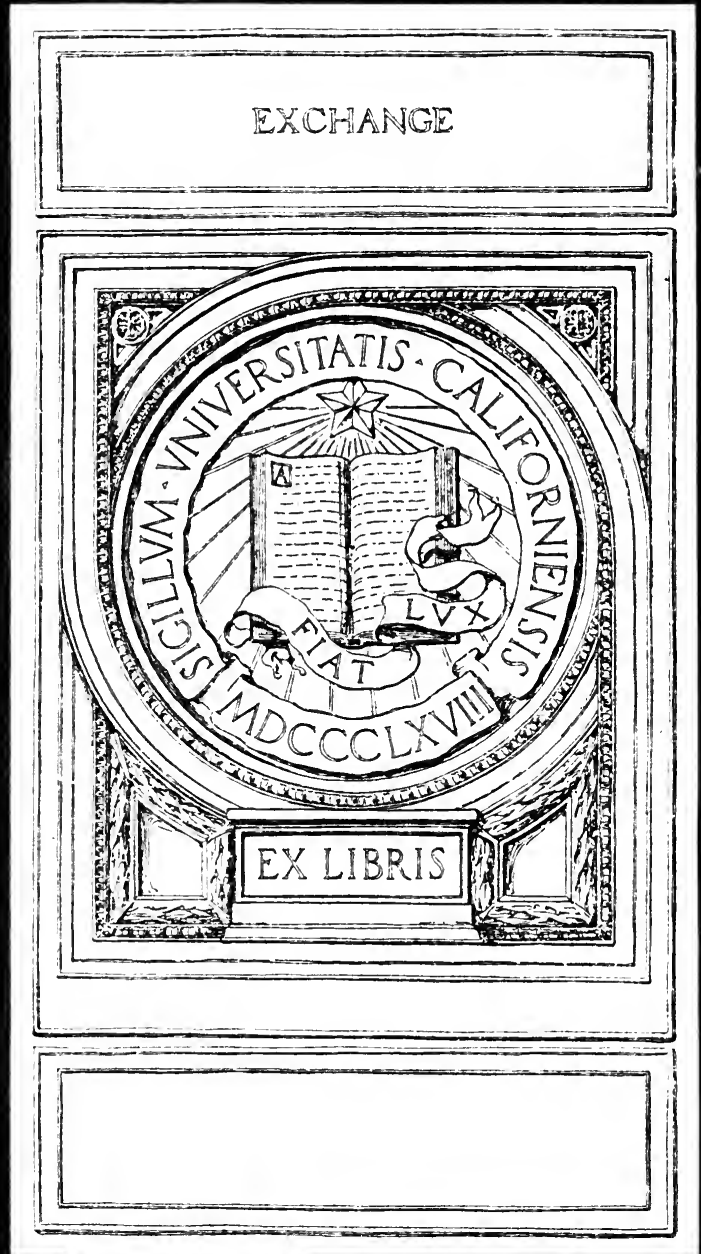




\section{THE RELATION OF FATIGUE TO INDUSTRIAL ACCIDENTS}

A DISSERTATION

SUBMITTED TO THE FACULTY OF THE GRADUATE OF SCHOOL ARTS AND LITERATURE IN CANDIDACY FOR THE DEGREE OF DOCTOR OF PHILOSOPHY

(DEPARTMENT OF SOCIOLOGY)

BY

EMORY S. BOGARDUS

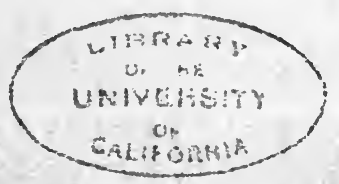

Reprinted from

The AMERICAN JouRnal of Soctology, XVII (IgII-I2)

CHICAgo, I9I2 


$$
\text { (1D) } 33^{62}
$$

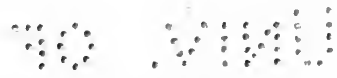

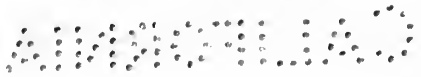

Composed and Printed By The University of Chicago Press

Chicago, Illinois, U.S.A. 


\section{INTRODUCTION}

The discussion of any question relative to industrial accidents remains incomplete if the influences and possible consequences of fatigue are not considered. ${ }^{2}$ The origin of the problem of fatigue in industry is to be found in connection with the industrial revolution. Before the introduction of the factory system, employer and employee usually worked side by side as companions. The blacksmith had a helper or two ; the farmer had his "hired hand"; the shoemaker, an apprentice. Tools were simple; accidents, rare. The occupations were usually not hazardous; the existing dangers, if any, were obvious. People generally worked from "sun to sun," but in a more or less leisurely fashion.

When hand-driven tools were supplanted by power-driven machinery, and the home gave way to the factory as the unit of production, the long hours of labor were carried over. Monotonous, speeded-up processes took the place of interesting forms of work at a leisurely rate. At about the same time, work by artificial light was made possible. Consequently, work-hours, instead of being shortened to suit the new mechanical processes, were "considerably lengthened, and in the case of child labor particularly, to a cruel degree."3 As late as 1842 , for instance, the working day in cotton mills (United States) was fourteen hours long. When domestic industry was supplanted by the factory system, not only men but women and children in large numbers were subjected to the monotonous, speeded-up processes of machine labor and for extremely long hours. Herein is to be found the origin of the problem of fatigue in industry.

From such a beginning, the fatigue problem developed rapidly under cover of the laissez-faire philosophy of the last century. It was held by the theorists that if labor conditions became too

${ }^{2}$ I am indebted to Professor C. R. Henderson for suggesting this problem.

${ }^{2}$ A. Imbert. 14. Intern. Kongr. f. Hyg. u. Demog., II, 634 .

${ }^{3}$ Adams and Sumner, Labor Problems (Macmillan, 1908), 515. 
severe in one factory, the laborers would leave and flock to other factories where more favorable conditions existed. But such freedom of choice was not actually open to working men and women, for the severe labor conditions came to prevail generally. In this way, under the protection of laissez faire, the fatigue problem came to assume amazing proportions. Thus it has escaped social vigilance until within the last few years, and today it presents almost insuperable difficulties. It has recently been said that among the many problems of industrial hygiene, the most important has hitherto been most neglected - the problem of industrial overstrain. Josephine Goldmark designates overfatigue as "the commonest and most subtle danger of occupation," and says that in the United States this danger

has not yet been faced nor even fairly stated; yet no one element of industry is more fraught with peril for workers. Indeed, overfatigue or exhaustion - surmenage as the French call it-affects every department of life, physical and economic, mental, moral. It predisposes to disease; it destroys intelligence and all the habitual restraints; it cuts down output and impairs its quality; it invites industrial accidents. It affects not only workers in admittedly dangerous occupations but all workers-every man, woman, and child employed for excessive working hours."

The problem of fatigue in industry has at least six phases: (a) the relation of fatigue to industrial accidents; (b) fatigue and industrial inefficiency-presumably poorer work and less work is done in the last hour of a day's labor than in other hours; (c) fatigue and contagious diseases-an overworked laboring man or woman is probably more susceptible to pneumonia, tuberculosis, typhoid fever, than is a person whose vital resistance is normal; $(d)$ fatigue and nervous diseases-the evidence indicates that long hours of feverish haste among factory workers lead to nervous breakdown; $(e)$ fatigue and future generations - the children of overworked parents are likely to be physical weaklings; $(f)$ fatigue and morals of working people-long hours of monotonous labor probably increases the susceptibility of the human organism to harmful temptations.

The first phase of the general fatigue problem-with which

‘Josephine Goldmark, "The Study of Fatigue," Survey (1909), XXII, 534. 
this report is concerned-has not yet been formulated, as far as the writer is aware, as a distinct problem in itself. Investigations relative to accidents have had largely to do with the objective causes; while the more deep-seated and perhaps the more primary causes have been neglected. In spite of the advance which has been made in this country within recent years in the introduction of safety appliances and of a system of factory inspection, an enormous human sacrifice is annually made to production; herein lies the chief reason for this study. A few typical facts are subjoined.

Crystal Eastman found that 526 lives were sacrificed to production in one year, ending June 30, 1907, in Allegheny County, $\mathrm{Pa}$. With respect to accidents, her report says there has been no respite-each year has turned them out as surely as the mills ran full and the railroads prospered. In Allegheny County alone the number would reach 5,000 in ten years-enough to make a small city of cripples. ${ }^{5}$

After carefully investigating the returns from the labor offices of nine states, ${ }^{6}$ Gilbert L. Campbell finds that these reports show clearly that in the year 1907 , for example, a total of at least 43,7 3 industrial accidents befell working-men in the states cited, and that 3,436 of these accidents were fatal. ${ }^{7}$ In regard to accidents befalling railway employees, Mr. Campbell bases an estimate on the statistics gathered by the Intenstate Commerce Commission and states that during the seven-year period, 1902-7 inclusive, 335,974 employees were injured and 23,895 were killed. Of the trainmen alone 218,082 were injured and 14,888 killed.

In a given year the trainman has one chance in 127 of death, and one in 9 of injury. Seven years in the train service offer him one chance in I 8 of death, and if his place is one of average danger present a practical certainty of injury.

Industry may be charged not only with extravagance of killing and

${ }^{5}$ Crystal Eastman, Work Accidents and the Law (Charities Pub. Com., I9ro), 12.

${ }^{6}$ These nine states are: Minnesota, Iowa, Wisconsin, Illinois, Michigan, Ohio, Pennsylvania, New Jersey, and New York.

' Gilbert L. Campbell, Industrial Accidents and Their Compensation (Houghton Mifflin Co., I9I I), 9, IO.

Ibid., 15. 
maiming yearly thousands of workers, but it seems to choose for its victims many persons in the prime of manhood, normally with years of life before them, and with obligations but partly discharged to wives and children.?

Approximately 30,000 wage-earners are killed by accidents every year and at least 500,000 more are seriously injured (in the United States). ${ }^{10}$ John B. Andrews says that industry "maims more men than war ever did." Professor H. R. Seager states that the United States "shows every year a larger proportion of industrial accidents on its railroads and in its mines and factories than any other civilized land."11 Moreover, the resultant suffering and denial of opportunity to the wives and children of the daily increasing numbers of the prematurely dead and of the industrially maimed and handicapped for life are beyond computation. Professor Henderson asks: "Who can set a price on mangled limbs, tortures of men caught in cogwheels and bands, sawed asunder in mills, and the sorrow, anxiety, and despair of their impoverished families?"12 The enormous blood-tax which industry daily levies upon wageearners makes necessary new forms of careful investigation of the causes, one of which may be fatigue.

Difficulties arise at the outset of this inquiry. Fatigue is an illusive phenomenon. It varies with different workmen, with different kinds of work, with different days. It also appears that fatigue develops insidiously and often without the knowledge of the worker. Moreover, physiologists and psychologists disagree as to the nature of the fatigue processes.

Another kind of difficulty is common. When three wellknown social and economic writers (two Americans, one European) were communicated with, and asked for the references on the strength of which each had published the definite statement that more accidents occur in the last hours of work than in other hours, no one of them could cite such references. One of the frank confessions reads: "For the statement you quote, I imagine now that I did not have at hand the European.statistics, and did

O Op. cit., $2 \mathrm{I}$.

s* J. B. Andrews, "A Clinic for Industrial Diseases," Survey, XXV, 269.

$"$ H. R. Seager, Social Insurance (Macmillan, I910), 25.

"C. R. Henderson, "Wood-Workers and Their Dangers," World To-Day (I910), XIX, 972. 
not know where to find them; or I would have been more specific in referring to them."

Attempts to collect new data are difficult. Some employers have established a monopoly of knowledge and of social factsfacts concerning which the public should know. One day in August, I9Io, the writer explained to the attorney of a company employing hundreds of men that data regarding accident-hours were wanted. When the attorney had assured himself of the bona fide nature of the inquiry and that personal data, such as names, would be held strictly in confidence, he gave the writer access to accident records covering a period of years and giving. the exact time of the accidents. A tabulation of the hours when these accidents occurred was scarcely begun when a high official of the company happened to enter the attorney's office. Almost at a glance he unjustifiably read much into the situation and grüfly said: "This is irregular; we can't have it." A courteous explanation that the sole aim was to secure social facts elicited no response from this apparently anti-social individual other than a curt abbreviation of his first remark.

An investigation of the relation of fatigue to industrial accidents raises difficulties which increase on every hand. On one side is a series of physiological and psychological phenomena; on the other, an equally involved series of objective and social factors. At this point the question might easily have been raised as to whether further study would bring definite results. It was from such an attitude that further inquiry was made. A preliminary study of this phase of the general problem of fatigue in industry raises six important groups of questions, which will be considered in as many sections.

(a) While considerable research work has been done in connection with a study of fatigue, each of the inquiries has treated the phenomenon more or less independently of its social significance. Although the physiologists and especially the psychologists have contributed extensively to the study of fatigue, ${ }^{13}$ the writer has not seen a description of the manner in which and the extent to which fatigue is psychically related to accidents in

${ }^{{ }^{3}}$ For example, the description of the investigations of Kraepelin and of his colaborers in the laboratory at Heidelberg fill several large volumes of the Psychologische Arbeiten. 
industry. The discussions regarding fatigue generally stop with analyses of subjective processes. They do not deal with fatigue as a social problem or consider it in relation to a special group of social phenomena-such as accidents. ${ }^{14}$ Is there not a need, then, for a concise description of what the physiologists and also the psychologists have discovered that may be used in a study of fatigue as a cause of accidents? The question that is raised here calls for the formulation of a law of the development of the fatigue processes which accompany continued work, in so far as they may be related to accidents.

(b) In the next place, how does modern industrial labor affect the normal development of fatigue-in what ways is the development of the fatigue process hastened in the case of presentday working people, and why; and what are the observable circumstances under which these processes result in accidents? (c) Can the subjective fatigue processes be measured by means of controlled experiments in terms comparable to the observable conditions preceding accidents, and thus be causally related to accidents?

(d) The fourth question is: What are the objective correlates of fatigue in terms of actual accidents, or to what extent do statistics of the hours when accidents occur isolate fatigue from the other and more evident causes? (e) Has overfatigue attracted attention to itself to the extent that men of the business and legal world have pronounced it a cause of accidents? Specifically, to what extent do investigations of the causes of railway accidents, for example, by the Interstate Commerce Commission, isolate fatigue as a cause of accidents; and have the courts indicted fatigue as a cause of accidents?

(f) In the last place, should not all the facts relative to this problem be brought together in a unified whole? The facts derived (I) from a study of the normal development of fatigue, (2) from a study of pathological fatigue under modern industrial conditions, (3) from an experimental study of fatigue under

"The Brief in Defense of the Ten-Hour Law for Women in Illinois (1909), by Louis D. Brandeis, assisted by Josephine Goldmark, contains an excellent compilation of opinions from European and American sources regarding different social phases of the fatigue problem. The brief has served as a valuable reference work in the preparation of portions of sections II, III, and $\mathrm{V}$ of this study. 
controlled conditions, (4) from a statistical inquiry into accidenthours, and (5) from a compilation of legal opinion relating to the problem in hand-will be summarized and presented in defense of the proposition that fatigue is a cause of industrial accidents. To the extent that the facts show that fatigue is a causal factor of work-accidents, a modified method of combating their prevalence will be necessary. One general suggestion in this connection will be made. In the next section a description of the development of the fatigue processes which may lead up to and culminate in industrial accidents will be undertaken.

\section{RELATED FATIGUE PROCESSES ${ }^{\mathrm{x}}$}

Mosso was among the first to point out in a scientific way the fatal struggle between the machine-operative, subject to the laws of fatigue and exhaustion, and the machine itself, powerful and indefatigable. ${ }^{2} \mathrm{He}$ designates fatigue as a chemical process. The earliest experiments relative to fatigue were of a chemical nature.

Normal muscle-tissue has the power of changing the sugar brought to it by the blood into glycogen $\left(\mathrm{C}_{6} \mathrm{H}_{2} \mathrm{O}_{6}-\mathrm{H}_{2} \mathrm{O}=\right.$ $\mathrm{C}_{6} \mathrm{H}_{10} \mathrm{O}_{5}$ ). The muscle stores away the glycogen thus formed and it becomes a constant constituent of a normal muscle. The glycogen which the muscle has stored away while resting is consumed during activity. If the activity is sufficiently prolonged, the glycogen disappears entirely and exhaustion of the muscle is likely to result. It has been shown by verified experiments that if most of the carbohydrate (or glycogen) be removed from the body of an animal, the organism gives the symptoms of "pronounced fatigue."3 The same result holds true of individual muscles.

Without doubt, during muscle activity there is a constant

${ }^{x}$ This sketch of the fatigue processes is such as appears preliminary to the formulation of a causal law of fatigue underlying industrial accidents. Only the material germane to a clear understanding of the chapters which follow is presented here.

a "Le savant professeur (Mosso) nous montre la lutte inévitable fatale, entre la machine puissante, infatigable et aveugle et l'ouvrier chargé de la conduire, de la guider, mais qui lui, organisme vivant, est soumis aux lois de la fatigue et de l'épuisement."-P. Langlois, Introd., trans. of Mosso's La fatigue intellectuelle (Paris, 1904), I2.

'F. S. Lee, "The Nature of Fatigue," Pop. Sci. Mon., LXXVI, 185, 186. 
drain upon the material from which muscle-energy is obtained. ${ }^{4}$ There is a growing loss of power to absorb nutriment from the blood, and a continual tearing down without equal building up. After repeated muscle contractions, the processes of katabolism (tearing down) are in excess of those of anabolism (building up); and prolonged muscular activity is accompanied by an "exhaustion of energy-yielding material." It should be added that this exhaustion process goes on not only in the groups of muscles which are being visibly used, but also in the groups of muscles in different parts of the body which are held tense and unrelaxed in guiding the groups of visibly working muscles.

Besides, the mentioned structural changes which accompany work ${ }^{5}$ occur not only in muscles but in nerve-cells. Physiological evidence indicates that during mental and muscular activity nerve-cells undergo actual structural changes. ${ }^{6}$ (a) The nucleus of the nerve-cell shows marked decrease in size; it changes from a smooth and round to a jagged, irregular outline; it loses its open, reticulate appearance. (b) The protoplasm of the nerve-cell shows a slight shrinkage, and undergoes vacuolation. (c) The cell capsule suffers a decrease in the size of its nuclei. These results were obtained from a study of spinal ganglion and brain-cells electrically stimulated and of those in a state of fatigue produced normally. For certain of these nerve-cells, Hodge found that a period which varied from seven to twenty-four hours was necessary before the cells returned to their previous shape and appearance.

Guerrini's experiments corroborated Hodge's results. He examined microscopically the brain-cells of animals fatigued by muscular work. The more the animal had been fatigued

the more profoundly altered the nerve-cells of its cerebral or cerebellar cortex were found to be. These are, briefly, the modifications which fatigue

4W. H. Howell, A Text-book of Physiology (Saunders Co., 1909), 71.

s It is not intended to make a definite distinction here between mental and muscular fatigue. In all forms of hazardous labor the mental and muscular factors are both inextricably involved as parts of one bodily process, but of course in varying degrees.

'See D. F. Hodge, "A Microscopical Study of Changes Due to Functional Activity in Nerve Cells," Jour. of Morphol., VII, 95-r68; also "Some Effects of Electrically Stimulating Ganglion Cells," Amer. Jour. of Psych., II, 376-402; also A. G. Levy, "Fatigue of the Cerebral Motor Cortex," Brit. Med. Jour. (r900), 74I. 
produces on the microscopic structure of the nerve-cell, and more evidently in that of the cerebral than in that of the cerebellar cortex, and most of all in the structure of those nerve-cells which correspond to the motor zones. ${ }^{7}$

This progressively exhaustive chemical process has another significant phase for this paper. As a result of his experiments, Ranke came to the belief that certain substances which inhibited the power of muscular contraction were formed as a result of the chemical processes occurring during contraction. He named these, "fatigue substances" ("ermüdenden Stoffe").$^{8}$

In the extracts of normal muscle, parcolactic acid $\left(\mathrm{C}_{3} \mathrm{H}_{6} \mathrm{O}_{3}\right)$ is found but slightly, while the amount greatly increases during muscle activity. Mosso calls attention to the fact that before the close of the I8th century Lavoisier and Sequin, by a series . of memorable chemical analyses, demonstrated that muscular work increased the amount of carbonic acid eliminated from the system. A laborer expires nearly twice as much carbon dioxid during a working day as during a resting day. The carbon dioxid results from the oxidation of the carbon found in the constituents of the muscle. Monopotassium phosphate $\left(\mathrm{KH}_{2} \mathrm{PO}_{4}\right)$ is another of the important and definitely determined fatigue substances. ${ }^{9}$ These substances seemed to be formed also in the nerve-cell during activity. ${ }^{10}$

In the next place, the fatigue substances mentioned exert $a$ poisonous and paralyzing effect upon the whole organism. Both parcolactic acid and carbon dioxid "when in any but small quantity are inimical to protoplasmic activity, and furthermore, . . . . a muscle under their influence shows the very same physical symptoms that are shown by a muscle fatigued through work." After investigating a large amount of testimony from physicians and physiologists, both European and American, Brandeis and Goldmark state :

They [the unexpelled products of fatigue] circulate in the blood, poisoning brain and nervous system, muscles, glands, and other organs until normally removed by the oxygen of the blood, by the liver or kidneys. .... When they exceed their physiological or normal amount, exhaustion results. ....

'Guido Guerrini, "Preliminary Account of the Influence of Fatigue on the Structure of the Nerve-Cells," Lancet, II, I087.

'J. Ranke, Tetanus (Leipzig, 1865), chap. xv, "Die einzelnen ermüdenden Stoffe."

' Howell, op. cit., 70.

so Ibid., I39. 
In extreme instances of overexertion death results, not from sheer exhaustion of the heart, but from chemical poisoning due to the unexpelled products of fatigue. ${ }^{11}$

In this connection, Dr. H. B. Favill says:

Any living organism will die promptly if the waste products (including the fatigue substances) from its life processes accumulate. . . . Laboratory research, verified by many competent observers, indicates that there are created in the process of muscular work ... substances of a nature distinctly poisonous. ${ }^{12}$

Besides the fatigue substances mentioned, Weichardt states that muscular contraction produces a definite toxin (kenotoxin). ${ }^{13} \mathrm{He}$ found kenotoxin in the muscle juices ("Muskelpreszsaft"); and in addition to the known fatigue substances. When injected into an animal, kenotoxin produces fatigue; in large doses it causes death ("wirkte er ermüdend und in groszen Doses, tödtlich"). Weichardt has definitely isolated both kenotoxin and its antitoxin ("beide Substanzen, habe ich isoliert dargestellt und $z u$ ausgedehnten Versuchsreihen verwendet"). These results have been verified by Dr. Wolff-Eisner. ${ }^{14}$ They add weight to the fact that the known fatigue substances possess a toxic and paralyzing nature.

It appears that the fatigue poisons accumulate first, not in the muscles actually moving but in the groups of tense, nonmoving muscles, which are used in guiding the given activity. These muscles are poorly irrigated. But sooner or later the fatigue substances accumulate in the moving muscles, even though these are better irrigated. The toxins also circulate in the blood throughout the body. Howell describes the twofold chemical process accompanying work as $(a)$ an exhaustion of energyyielding material, and $(b)$ an accumulation of the products of katabolism (the fatigue substances). ${ }^{15}$ Verworn refers to the

${ }^{x x}$ L. D. Brandeis (assisted by Josephine Goldmark), The Brief in Defense of the Ten-Hour Law for Women in Illinois (1909), 77, 78.

${ }^{12}$ H. B. Favill, "The Toxin of Fatigue," Survey, XXIV, 769.

${ }^{{ }_{3}}$ See W. Weichardt, "Ueber das Ermüdungstoxin und Antitoxin," Münch. med. Wochenschr., LI, 2122-26, LII, I234-36; "Ermüdungs- und Ueberermüdungsmaszmethoden," Deutsche Vierteljahrschr.f. offentl. Gesundheitspfl., XXXIX, 324-34.

" See A. Wolff-Eisner, "Ueber Ermüdungs- und Reduktionstoxine," Centralbl. f. Bakteriol., I Abt., XL, 634-44.

${ }^{25}$ Howell, op. cit., 7 I. 
using up of energy-yielding material as culminating in "Erschöpfung"-a literal exhaustion; and to the production of fatigue substances as resulting in a state of "Ermüdung." 16 The change that takes place in the reaction of an active muscle, in the size of an active nerve-cell, and in the amount of waste material thrown off by the organism when it becomes active, leaves little room to doubt that there is a direct relation between structural changes and activity.

2 This conclusion brings up the related functional changes accompanying work. For the purpose of this study, the fatigue process may be treated as centering around the objective phenomenon of increasing muscular inaccuracy. Because of the using up of muscle material and because of the accumulation in the muscles of the fatigue-toxins, a given group of working muscles gradually become less able to respond to the demands made upon them by the psychical-neural apparatus. If rapidly repeated stimuli of equal strengths at equal intervals be applied to a muscle, it is found that at first the contractions increase in extent (forming the "treppe"), that after a certain period the contractions begin to diminish steadily in height until finally the muscle will fail to respond to the stimulus. This progressive loss of irritability in the muscle, caused by repeated activity, has been designated as fatigue. ${ }^{17}$

Ergograph experiments (where the stimulation of the muscle is not artificial, but voluntary) show that after a state of complete fatigue has been reached with a given task, a very long interval is necessary for the muscle to make complete recovery. ${ }^{18}$ Mosso lays stress on the fact that Professor Maggiora proved that two hours' rest is necessary before the fatigue traces are completely removed from the flexor muscles of the fingers after they have been exhausted by a series of contractions in the ergograph. ${ }^{19}$

Maggiora found that the last smaller contractions of muscles are more exhaustive than the first large contractions. ${ }^{20}$ After

${ }^{36}$ Max Verworn, Allgemeine Physiologie (Jena, 1909), 557.

${ }^{37}$ Howell, op. cit., 34, 35 .

s Ibid., 49. The ergograph is a special instrument devised by Mosso, by means of which the muscle is given a specific work to do, such as lifting a weight.

"A. Mosso, Fatigue (Paris, I904), trans. by the Drummonds, 50.

20 A. Maggiora, "Ueber die Gesetze der Ermüdung," Arch. f. Anat. u. Physiol. (189o), 213. 
muscles are completely fatigued, still further efforts to contract them greatly prolong the period of complete recovery. Work which calls for contractions of tired muscles is much more injurious ("viel schädlicher") than greater muscular tasks under normal conditions. ${ }^{21}$ Verworn states that a fatigued muscle requires a considerably longer time ("unvergleichlich mehr Zeit") for relaxation than does a normal muscle. ${ }^{22}$ It is the long interval of recovery, a period unduly long for the removal of the katabolic products due to the activity of a single muscle, which leads to the belief already cited that fatigue is partly due to consumption of muscle-material itself, which has to be replaced by anabolic or building-up processes before the muscle is entirely free from fatigue effects. ${ }^{23}$

Other things being equal, the rate at which the working muscle becomes less responsive to stimulation depends $(a)$ upon the rapidity and ( $b$ ) upon the difficulty of the given piece of work. Kronecker found that the more rapid is the rhythm in which muscular contractions are produced, the more rapidly does the height of these contractions diminish; and vice versa. ${ }^{24}$ By using the ergograph, Winfield $\mathrm{S}$. Hall found that if a muscle be given a load proportional to the actual strength of the muscle and if the muscle be allowed to rest from the strain of the weight during the period of relaxation, the time of the fatiguing process may be indefinitely prolonged. ${ }^{25}$

Not only do working muscles become less able to respond to stimulation because of fatigue, but they receive less and less efficient stimulation from the psychical-neural apparatus. It appears that with the exhaustion of energy-giving material and with the accumulation of the toxic fatigue substances in the parts used and in those portions of the muscles located at any place in the body that are under tension in guiding the activity of the muscles that are working, inhibitory impulses ascend along the afferent fibers, with which every muscle and tendon is supplied, to

"Op. cit., 21 1 .

"2 Max Verworn, op. cit., 548.

${ }^{23}$ W. H. Howell, op. cit., 7 I.

${ }^{24}$ See C. S. Yoakum, An Experimental Study of Fatigue (The University of Chicago Press, 1909), 3 .

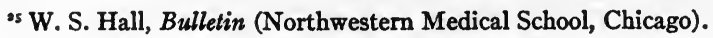


the motor centers of the cortex and cord. Myers says that the afferent fibers running from the muscular (and other) tissues of the body to terminate around the cells of the motor nuclei of the cord, bulb, and mid-brain, play an important part in reflexly co-ordinating muscular action. ${ }^{26}$ The various motor centers of the cord which control the movements of flexion and extension are alternately excited or inhibited, owing to the play upon them of afferent impulses peripherally derived from the movements themselves. Whatever disturbs these afferent impulses disturbs muscular co-ordinations. The using up of muscle material and the accumulation of fatigue substances appear to increase the inhibitory action of afferent impulses.

The neural apparatus also becomes less efficient in guiding the working muscles because of the structural changes going on in the nerve-cells. Dearborn says that nerve-cells do become exhausted progressively, however slowly, even in cases where their blood-supply is ample and their vigor normal. ${ }^{27}$ Tigerstedt says that by a method especially adapted to the purpose it may be shown that the nervous mechanism is being greatly strained before there is any sign of fatigue in the external work done. ${ }^{28}$ In summing up the situation regarding nerve-cell fatigue, it may be said that it seems probable that under normal conditions some portions of the nerve centers remain in more or less constant activity during the day without showing a marked degree of fatigue, just as muscles remain in a more or less continuous state of contraction throughout the waking period. ${ }^{29}$ But when the nerve centers are strongly stimulated the fatigue is more marked "because the processes of repair in the nerve centers cannot then keep pace with the processes of consumption of materials." 30

Another factor which affects the efficiency of the neural apparatus in guiding the active muscles, has been mentioned, namely, the poisoning and paralyzing effect of the fatigue substances

26 C. S. Myers, Experimental Psychology (Longmans, Green \& Co., 1909), 186.

" G. V. N. Dearborn, "On the Fatigue of the Nerve Centers," Psych. Rev., IX, I82; see also W. H. Burnham, "The Problem of Fatigue," Amer. Jour. of Psych., XIX, 385. 446.

${ }^{28}$ R. Tigerstedt, A Text-book of Human Physiology (Appleton, 1906), trans. by Murlin,

" Howell, op. cit., 138 .

${ }^{30}$ Ibid . 
which circulate through the brain and other centers of control. The structural and functional fatigue changes which have been described may be briefly summarized at this point. Not only do muscles become less responsive to stimulation (because of the using up of energy-giving material and because of the paralyzing effects upon them of the fatigue substances), but the muscles receive less and less efficient stimulation from the neural apparatus (because of the effects upon the neural apparatus by the inhibitory impulses from both the tense and the moving muscles, by the structural changes in the spinal ganglion and central nervecells, and by the poisonous fatigue substances circulating through the higher neural centers).

The combined effects of these forces result in increasing muscular inaccuracy. Muscular co-ordinations become seriously hampered and irregular. The loss of control over the muscular co-ordinations consists first in "the immeasurably short shifts and 'blockings' of the more finely adjusted musculature ... . on to the grossest muscular contractions that finally cease to respond to the effort of the will."31

Loss of muscle control as indicated by the progress from blocking of the more finely adjusted musculature on to failure to make the grossest muscular contractions is not adequately represented by a continuous descending slant. Increasing fatigue when brought to the notice of the worker leads to temporary spurts, that is to say, to an increase in the volitional strain or attention which he brings to bear on his task. Although the fatigue process may go on for a time unnoticed, it sooner or later appears in consciousness in the form of "sensations." These sensations may arise first as feelings of effort, then as feelings of strain, then as sensations of fatigue. ${ }^{32}$ The fatigue sensations are warnings. They indicate that the organism demands "a shift in the working mechanism." By tremendous effort, a fatigued worker may for a short time bring to his labor a striking degree of volitional attention.

These spurts appear irregularly, and there are alternating and irregular periods of depression or bad spells when the worker

"Yoakum, op. cit., Ir4.

32 Ibid., II7. 
is less able to give attention and when the co-ordinations are less likely to be correct than during the periods of volitional strain. Beyond doubt, the periods of depression are due to flagging interest and increasing fatigue. ${ }^{33}$ Hence, during uninterrupted work and as soon as fatigue effects predominate over skill due to practice, there sets in an irregularly decreasing control over muscle co-ordinations. The time at which fatigue is likely to overcome practice during a given period of work depends among other things upon the rate and difficulty of the work, as already noted, for the given individual. At the beginning of a period of uninterrupted work there is likely to be uncertain muscle control, due to the necessity of getting "warmed up" and occasionally to nervous excitement attendant upon beginning a piece of work. Then for a certain length of time the muscle control is likely to be good-due to practice effects. ${ }^{34}$ When practice gain is overcome by fatigue effects, then muscular inaccuracy becomes a developing and important factor. During this period effort is expended in waves of force that approximate what Treves calls the irregular progress of mental fatigue rather than the regular decline of muscle power. ${ }^{35}$

Muscular inaccuracies may be of two kinds: one may keep up with the rhythm of work and make spatial maladjustments; or one may make accurate spatial movements, and fall behind the rhythm; or one may do both. Thus muscular inaccuracies may be not only of a spatial nature, but may involve a time element as well. Mosso says:

The time of physiological reaction .... is the name given to the interval between the occurrence of an electric spark, for instance, and our giving some sign of having perceived it, say by touching an electric button on which our hand rests. This short space of time.... represents the delay which takes place before we take account of one of the most simple forms of perception. . . . Fatigue has great influence on the duration of this reaction time. When such measurements are repeated without an interval for rest, the time before the response is given gradually increases. ${ }^{36}$

${ }^{33}$ Myers, op. cit., 194.

${ }^{34}$ A. Binet, La fatigue intellectuelle (Paris, 1898), 334; also E. Kraepelin, Philos. Studien, $\mathrm{XIX}, 459-507$.

${ }^{35}$ Yoakum, op. cit., 42.

${ }^{36}$ Mosso, op. cil., 205. 
A delay in promptness of reaction ${ }^{37}$ and a greater number of faults of memory and attention are noticeable after fatigue. ${ }^{38}$ It is almost impossible to be attentive when the brain, for instance, is fatigued. ${ }^{39}$ The length of time that ordinarily elapses before one responds with the hand, for example, to a touch on the foot may be doubled as a result of the effects of fatigue on attention. ${ }^{40}$

The effect of fatigue on attention-which is such an important factor in failure to make accurate muscular co-ordinationsappears to have its basis in the difficulty of maintaining the tensions which are guiding the given activity. ${ }^{-}$It is not possible to maintain one set of tensions long without physiological changes taking place. And any physiological changes may while they are still subconscious be the "cue" for a change of attention to some other topic of thought, a change which may involve a new set of tensions-and thus the process continues. Or, the physiological changes referred to may come to consciousness in the form of sensations of fatigue, and in this case there is a change of attention to the point of origin or to the sensations themselves, and vigilance over muscular movements is temporarily suspended. $\checkmark$ In the case of monotonous division of labor where the workman must attend continually to one single uninteresting point or part of a machine the same neural-muscular apparatus must be used, the same tensions must be maintained. The difficulty of maintaining this situation with little if any variation becomes increasingly great. If the task in hand requires constant attention, increasing muscular inaccuracy is likely to result-immediately due to the effects of fatigue on attention. The degree of muscular inaccuracy is determined partly by the inability of muscles to respond-according to their state of wear and tear and to the amount of fatigue substances which have accumulatedand partly by the inability of the neural apparatus to attend to

"7 "Reaction time includes such phenomena as $(a)$ the latent period in the sense organ, (b) time of transmission along the afferent nerve, $(c)$ resultant processes within the central nervous system, $(d)$ time of transmission along the efferent nerve, and $(e)$ the latent period in the muscle."-J. M. Cattell, "The Time Taken by Cerebral Operations," Mind, XI, 230.

${ }^{38} \mathrm{Z}$. Treves, "Dans quelle mesure peut-on, par des méthodes physiologiques, étudier la fatigue," etc., $13^{\circ}$ Cong. Intern. d'Hyg. et Demog., V, sec. 4 , ques. 3, p. 37 .

${ }^{30}$ Mosso, op. cit., 198.

40 Ibid., 205. 
the movements of the given muscles-according to the number of and the state of the tensions which can be relied upon in guiding the given activity. ${ }^{41}$

Muscular inaccuracy is increased especially where the regular effects of fatigue on attention are augmented by a general condition of overfatigue of the whole system, that is to say, by a state of chronic overfatigue. Pathological fatigue also results in "increasing inaccuracy of judgment," 42 which in turn increases muscular inaccuracy. Overwork blunts all the psychic activities and diminishes sensibility; and hence diminishes the precision of movements and the exactness of the rhythm. ${ }^{43}$

It has been pointed out in this section that uninterrupted muscular work results in using up of energy-yielding material of muscles and of nerve-cells, and in the accumulation of toxic waste substances, with an accompanying decrease in muscle irritability and activity, and inability of the neural apparatus to attend to muscle movements, i.e., with a corresponding and increasing irregularity in the co-ordination of muscular action. (The rate at which these various phases of the fatigue process takes place is dependent on the rate and difficulty-including monotonyof the given task.)

If stated in terms of the subjective conditions which the writer believes quite generally precede accidents, a summary of this chapter may be given psychological expression. The resultant and germane law of fatigue is: Uninterrupted muscular activity is accompanied by inaccurate muscular co-ordinations, which increase irregularly and at a rate largely determined by the speed and relative difficulty of the activity for the given individual.)

${ }^{42}$ See Yoakum, op. cit., 99-124; also Myers, op. cit., r $86 \mathrm{ff}$.

42 E. W. Scripture, "Researches in Reaction Time," Yale Studies, IV, 12-16, 69-75.

${ }^{43} \mathrm{~J}$. de Moor, 13. Intern. Kongr. f. Hyg. u. Demog., Pt. I, 5, sec. 4, ques. 3, p. 9. 


\section{RELATED INDUSTRIAL CAUSES OF ACCIDENTS}

After a study of the related subjective processes accompanying work had been made and after the formula given at the close of section II had been determined upon, the writer supplemented a previous limited experience by spending considerable time in visiting factories and shops in and about Chicago. The purpose was to test the conclusions already in mind and to observe more accurately the conditions which precede accidents. Eleven factories and shops were visited, representing as many forms of industry. ${ }^{1}$ Permission was obtained to wander leisurely about and thus unnoticed to observe operatives of dangerous machines while at work. About twenty types of dangerous machines were found. ${ }^{2}$ Three accidents were directly witnessed-two at soldering machines and one at a press and drill.

As a result of these observations it appears to the writer that the chief industrial conditions leading up to and culminating in accidents are those of monotony and speed and of unrelaxed tension, kept up for long hours. This process seems to result in increasing numbers and extent of muscular inaccuracies, which in turn appear to be the phenomena immediately preceding accidents. This view in more or less detail will be supported in this section.

Proof is hardly necessary to show that monotony and great speed characterize the conditions under which operatives of dangerous machines work. In most industries, labor is so subdivided that each worker has but one small part to do. This part is repeated thousands of times daily. To make a small sickle section, for example, requires thirty operations by as many men and boys. Certain parts of this process make vivid the factors of monotony and speed.

A man feeds metal sheets into a machine that cuts them out in a threecornered form, 20,000 per day . . . one motion is required for each sheet.

'These included the packing, canning, and steel industries; leather-goods and knitting establishments; steel-castings and box factories; various wood-working and metal-working concerns, and wagon shops.

2 Among these types are those represented by the press and drill, the press and die, revolving knives, saws, stamping and cutting machines of various forms, and soldering machines. 
The two holes of the sickle section, when punched, are slightly enlarged on one side to receive the head of the rivet, 7,000 per day. Along one side of the room in which the edges of the sickle section are beveled are arranged a row of grindstones six feet across. In front of these whirring stones sit a line of powerful, heavy-faced men, not a spark of animation in their faces. They are each doing the same thing; they drop one of these plates into the slot of the frame, shove the frame against the rapidly revolving stone and then draw it back; drop, shove, draw back . . . 5,000 times each day. In the room where the sections are serrated, a row of young men stand, feeding machines which run at great speed and with deadening noise. These machines cut the teeth on the bevel edge of the plate, 7,000 plates a day.

These monotonous, speeded-up operations in connection with dangerous machinery are found in "the manufacture of nearly every article of use or comfort with which our lives are surrounded; in the manufacture of that piano, the chair you are sitting on, the watch in your pocket, the car you ride in, the sewing machine, the meat you ate for your breakfast this morning."

In the canning factories of Pittsburgh, for instance, where tops for cans are cut from sheets of tin, the foot-press operator puts the sheets in the press, gauges it so that it will fall evenly, gives a quick pressure of the foot in order to clip the tin for each top. This quick pressure and accompanying hand movements are repeated "forty times a minute, 24,000 times a day."3 Ernst Abbe points out that

with this sameness ("Gleichförmigkeit") and continually recurring monotony ("Einförmigkeit"), we also get the continuous ("fortgesetzte") fatigue of the same organ, of the same nerve centers, and of the same part of the brain ... . because all that is to be done, whether muscular or mental work, must be constantly repeated ("sich wiederholen") in the same manner from morning to night, day by day, and week by week."

Today, the necessary rapidity of monotonous motions fatigues workers and causes accidents. Dr. Thomas Oliver regrets the attempt to americanize shipbuilding in England for the reason that this "rushing" is a cause of serious accidents. ${ }^{5}$ Professor G. Pieraccini and Dr. R. Maffei, Florence, state that piecework, which necessitates higher speed, tends, both in itself and

${ }^{3}$ Eliz. B. Butler, Women and the Trades (Charities Pub. Com., I9o9), 36.

- E. Abbe, Gesammelte Abhandlungen (Jena, I906), III, 225.

$5 \mathrm{~T}$. Oliver, Diseases of Occupation (London, rgo8), 3. 
together with the fatigue that ensues, to favor the occurrence of labor accidents. ${ }^{6}$ It is no exaggeration to say that the pace kills and injures more people than labor per se. To the extent that the stupefying effects of monotony and the confusion attendant upon "speeding up" are added to the regular development of the fatigue process, loss of muscular control and danger of accident are increased.

A characteristic phase of monotony and speed is unrelaxed tension of the worker. Arlidge says that the fatigue of machine operatives is more the fatigue of watching than that of working. ${ }^{7}$ From a psychological standpoint, it is impossible to attend to very many things at a time or to attend to one thing for very long at a time. It is especially fatiguing to keep the attention on a simple process which presents no new phase, but which is a continuous repetition of a few simple movements hour by hour. It is true, of course, that these movements tend to become automatic; but when they must be made in close proximity to dangerous and rapidly revolving tools, a certain degree of voluntary attention must be exercised, or else injury will result during a moment of inattention.

Professor Henderson states that the speed of saws, for instance, is a significant factor in increasing danger, "because the swift movement increases the strain upon attention and so $X$ rapidly exhausts nervous energy." 8 The relaxation of tension which sometimes results in serious injury, says Elizabeth B. Butler, may be accounted for by the hurry of the worker who is usually ambitious, or by the weariness toward the end of the five hours' continuous work. ${ }^{9}$

2 Operatives of machinery become accustomed to the presence of danger and hence less on their guard against the effects of fatigue on attention. Cadbury says that workers accustomed to danger are apt to look away to talk to their companions and in

- See Brandeis and Goldmark, Ten-Hour Law for Women, 75.

'J. T. Arlidge, The Hygiene, Diseases and the Mortality of Occupations (London, 1892).

'C. R. Henderson, "Wood-Workers and Their Dangers," World To-Day, XIX, 975.

'Eliz. B. Butler, op. cit., 22 . 
a moment of relaxed tension the hand is caught under the machine.

The incessant noise of the machinery, the excessive monotony of the $X$ work, and above all, the long hours, which are too often spent in an illlighted and ill-ventilated atmosphere-all tend to produce a depressing and deadening effect which cannot fail to destroy the alertness of attention. ${ }^{10}$

In the steel mills, for example, an alert mind is the finst requirement for safety. ${ }^{11}$ There, as elsewhere in connection with dangerous work, attention is focused more on the proper accomplishment of the work than on self-protection. But attention to the matter of self-protection in steel mills is comparable to an attempt to dodge bullets on the battlefield. Neither a steelworker nor a soldier of that type can long retain the respect of his fellows. Attention to self-protection is bound to be secondary and incidental; but to insure the workman's safety it must be constant and keen. However instinctive this vigilance may be, it cannot be considered unfailing. The speed and intensity of the work, the heat and noise of the steel mill, the weariness of the workers, "all these things tend to numb the faculties most needed for protection."12

As a result of continuous and unrelaxed tension, the fatigue processes go on insidiously. "The onset of fatigue is often unperceived. The tension in modern industry calls out the voli$x$ tional power which urges on a fatigued worker, intensifies application, and minimizes the sensation of effort, thus concealing fatigue. Kirkpatrick emphasizes the fact that a person often does not feel weary after his power to act has been very much decreased. ${ }^{13}$ The distinction which must be made between the sensations which supervene during the performance of the work and the lowered capacity for work as shown objectively by diminution in the amount of work executed is well known. Rivers says that there may be complete absence of any sensations of fatigue, when the objective record,shows that the

ro Edw. Cadbury and others, Women's Work and Wages (The University of Chicago Press 1907), 53 .

"Crystal Eastman, Work-Accidents and the Law (Charities Pub. Com., rgro), 9I.

"Ibid.

${ }^{23}$ E. A. Kirkpatrick, Fundamentals of Child-Study (Macmillan, 1909), 322. 
work is falling off in quantity, or in quality, or in both. ${ }^{14}$ The curve of organic fatigue follows a different outline than that which represents the production of voluntary work. ${ }^{15}$

Workmen are generally ignorant of the difference between the subjective development of fatigue, and its objective correlates. Unrelaxed tension in modern industry makes continuous and terrible demands on the human volitions. These, in turn, so intensify application and minimize warnings of overfatigue that the worker in the dangerous trades may suddenly through inaccurate movements find himself handicapped for life, or the wife and children may receive the unexpected message that their breadwinner has given up his life while serving at the post of duty.

The terrific mental strain due to monotony and speeding up is doubly vicious because of the fact of long hours, After a certain period of time, varying in length with different individuals, unrelaxed tension cannot be consistently maintained, uncertainty of movements increases, and danger of accidents multiplies. After making a careful investigation of work-hours, the National Conservation Commission says: "The present working day from a physiological standpoint is too long, and keeps the majority of men and women in a continual state of overfatigue. ${ }^{16}$ ... The manual worker through fatigue caused by long hours is in a continual state of overexertion."17

The situation is especially grave when the men and women kept in a continual state of overfatigue because of long hours are operatives of dangerous machinery. Further, in many industries where danger exists, the long hours of regular employment are supplemented by demands for "overtime" work during certain parts of the year. In Pittsburgh, for example, Elizabeth Butler found that many canning factories work every night until ten o'clock during the busy season, making a working week of over 72 hours. ${ }^{18}$ One manager admitted that the girls

" W. H. Rivers, The Influence of Alcohol, etc., on Fatigue (London, 1908), 2.

${ }^{3 s} \mathrm{~T}$. Oliver, Dangerous Trades (London, 1902), 117.

${ }^{16}$ Senate Document No. 4I9, 6rst Cong., 2d sess. (I9I0), 626.

${ }^{27}$ Ibid., 666.

${ }^{18}$ Eliz. B. Butler, op. cit., 39, 40. 
under his direction "worked 75 hours a week for two months every year." $\mathrm{He}$ added that the factory inspectors generally did not interfere; that they usually come around in September and after the holidays, and "they never see any overtime."19 In another factory where foot-press work was the chief type of labor, Miss Butler found that the employees are sometimes forced to work twelve and fourteen hours and "accidents are so frequent that the place has been characterized as a butcher shop."20 As another more or less typical illustration, a "hinge factory" may be mentioned where "overtime" work until halfpast eight is demanded almost throughout the year, there being no regular alternation of busy and slack seasons, but change according to orders. ${ }^{21}$ This irregularity is peculiarly true of the laundries, where in the latter part of the week "overtime" often lasts till eleven o'clock at night and later. ${ }^{22}$

In regard to railway employees, Crystal Eastman quotes a yard-master as follows:

Yardmen now usually work twelve hours, but when the yards are pressed, they often work the brakemen the sixteen-hour limit. And when a man works sixteen hours at a stretch, it often means that he has been awake eighteen or twenty hours, because there is a rule that a man must be called two and a half hours before he goes on duty. ${ }^{23}$

In the steel industry, the working day is usually twelve hours. A typical steel-worker says:

I've been twenty years at the furnaces and have been working a twelvehour day all that time, seven days in the week.... We work that way for two weeks and then we work the long turn and change to the night shift. The long run is when we go on at seven Sunday morning and work through the whole twenty-four hours up to Monday morning. ${ }^{2}$

John A. Fitch says that in 1907 he could find only about 120 eight-hour men among the 17,000 employees in the three largest plants of the Carnegie Steel Company in Allegheny County-a

"Ibid., 53. $\quad$ "Ibid., 233. ${ }^{2 x}$ Ibid., 225.

${ }^{22}$ See Clark and Wyatt, "Women Laundry Workers in New York," McClure's, XXXVI, $401-13$.

${ }^{23}$ Crystal Eastman, op. cit., 33.

${ }^{24}$ John A. Fitch, The Steel-Workers (Charities Pub. Com., I9r I), 170. 
trifle less than three-fourths of I per cent; "the prevailing workday is twelve hours for steel-workers." But the machinists being also repair men are sometimes obliged to work much longer, occasionally "a continuous twenty-four-hour period, while sometimes the men work thirty-four hours or longer without rest."25

Under normal conditions, fatigue would be overcome by adequate periods of rest, but in modern industry the workman is often denied the satisfaction of the physiological demands of fatigue. The human organism is so constructed that on rare occasions great reserve powers can be called out. Modern industrial labor is such that the reserve forces are called out daily. Mental strain and muscular fatigue are phases of the general fatigue process which develops with accumulative force, not only in the course of a day-period, but week by week. Joteyko says that it appears certain that fatigue accumulates "s'accumule progressivement" in the organism. ${ }^{26}$ "Fatigue is viciously progressive," says Dr. Favill. ${ }^{27}$ The actual structural changes, the impairment of the nutritive processes, the accumulation of poisonous products when taken together make up "an overwhelming incubus which no organism can long survive."28

Fatigue sometimes starts a vicious circle which leads to the craving of and indulgence in means for deadening fatigue. Liquor may drive away temporarily the fatigue sensations, but in the end it will leave the workman weaker, more subject, to trembling, to uncertain muscular control, and to injury.

Where fatigue is not balanced by adequate rest and nourishment, a deficit remains which is added to daily, which accumulates little by little; and the workman suffers increased susceptibility to accident. When the workman's strength becomes debilitated through overwork, he becomes incapable of attention, ${ }^{29}$ and defenseless against accident.

Present-day operation of dangerous machinery finally resolves itself into a competition of sensitive human nerves and

sop. cit., 174 .

${ }^{26} \mathrm{~J}$. Joteyko, "Participation des centres nerveux dans les phénomenes de fatigue musculaire," L'année Psych., VII, 166.

${ }^{27}$ H. B. Favill, "The Toxin of Fatigue," Survey, XXIV, 772.

${ }^{88}$ Ibid.

29 Th. Ribot, "The Psychology of Attention," Open Court (1896), 99. 
muscles against relentless and insensitive iron. ${ }^{30}$ The greater the number of hours that machinery must be operated per day, the feebler and more uncertain become the human forces that guide it. To the machine, time is nothing; to the working man and woman, each hour that passes beyond a certain limit offers increasing opportunity of injury and possibility of death.

While monotony, speed, unrelaxed tension, together with long hours, appear to be the leading general causes of industrial fatigue and hence of many accidents, it is proposed next to determine if possible the modus operandi of these general causes in bringing about accidents. In other words, what are the concrete, immediate conditions preceding accidents?

The writer has had access to the accident records of the state of Illinois for the year 1910. ${ }^{31}$ These records refer to accidents which necessitated that the injured lay off from work fifteen days or over, and they apply to the various manufacturing industries, the steel industry, and to many small plants and factories in Illinois. Of the total number of accident reports-some over 3,000-which were examined, 2,678 applied to non-fatal cases and gave a fairly accurate description of what happened preceding the given accidents. The remaining 40o-odd reports either omitted a description of the immediate cause or else gave it so inaccurately as to throw doubt on its value for this analysis.

The accident descriptions which apparently are accurate fall into two general classes. Class $\mathrm{A}$ includes the accidents where the immediate cause was evidently beyond the control of the injured-due to the breaking of machinery, to bursting of boilers, to chips of steel flying in the air. Typical statements illustrating this general class of accidents, as taken from the accident reports, are subjoined :

Scaffold collapsed.

Bolster flew out from under steam hammer.

Chip in eye.

Gas exploded.

Hot steam blew in eye.

$30 \mathrm{~T}$. Oliver, Dangerous Trades, Ix7.

sx I wish to acknowledge the courtesies shown me by Edgar T. Davies and his assistants in the office of State Factory Inspection (Chicago). 
Flying nail struck eye.

Struck in the face by piece of iron .... due to pulley breaking.

Hot scale blew into eye.

It is beyond doubt that in the cases represented by Class A, perfect subjective control preceding the given accidents would not have made escape possible.

Class B represents those accidents in which loss of control, varying from failure to make fine co-ordinations on to gross and bungling co-ordinations and to absence of movements which might have prevented injury, appears to have been a factor. Class $B$ is illustrated by the following typical descriptions:

Did not get her hand away soon enough and thumb was caught between billets.

Placed his finger too close to the cutter in putting in a piece of work.

Got his fingers under the die when it came down.

Caught hand under punch.

In some manner he got the small finger of right hand against the saw while the same was in motion.

Did not get his hand out of the way in time and his fingers were caught between plunger and edge of socket.

His hand slipped over the guard and caught in the knife.

His fingers went under the die when he accidentally tripped the press.

Caught his fingers in the die.

The injured accidentally placed his finger too close to the cutter in putting in a piece of work.

Automatically placed foot on treadle when tips of fingers were under die.

Hand slipped on to rip-saw.

Caught hands in knives.

Caught fingers between press and die.

Caught fingers between head of die and material.

Caught fingers in jointer while operating same.

Caught thumb between sheet metal and die.

Her finger slipped into the gear of her machine.

Of the 2,678 accident records which gave a fairly good description of what occurred immediately preceding the accidents, twelve records were of doubtful analysis. Four hundred and sixty-three cases or I 7.2 per cent belonged to Class $B$. Of the fatal-accident reports studied the number is too small to be of much value. Twenty fatal accidents or 37.8 per cent were of Class $\mathrm{A}$; and forty-one or $62 . \mathrm{I}$ per cent belonged to Class $\mathrm{B}$. 
Table I shows that a large percentage of non-fatal accidents is immediately preceded by muscular inaccuracies. In all cases of Class $B$, it is conceivable that if the injured had had perfect and ready control over muscular movements he would not have suffered accident.

TABLE I

Industrial Accidents Classified

\begin{tabular}{|c|c|c|c|c|}
\hline Year Igro & Doubtful & Class A & Class B & Total \\
\hline $\begin{array}{l}\text { Number............. } \\
\text { Percentage. . . . . }\end{array}$ & $\begin{array}{l}\mathrm{I} 2 \\
0.4\end{array}$ & $\begin{array}{l}463 \\
17.2\end{array}$ & $\begin{array}{l}2,203 \\
82.2\end{array}$ & $\begin{array}{r}2,678 \\
100\end{array}$ \\
\hline
\end{tabular}

In Section II it has been shown that the developing subjective fatigue processes inevitably result in increasing muscular inaccuracy; in the preceding paragraphs of this section it has been $x$ further shown that monotony, speed, mental strain in connection with long hours hasten the fatigue processes and hence greatly increase the loss of muscular control. In this section it is maintained that to the extent that fatigue is a primary cause of muscular inaccuracies, 82.2 per cent of the 2,678 accidents studied involved fatigue as a causal factor.

This proposition is illuminated by the fact that "the swift machinery of modern industry requires the attendants to push and guide the material in close proximity to merciless cutting tools."32 In Chicago the writer found twenty types of machines in connection with which the operatives were working so close to revolving saws, knives, drills, rollers, or at machines of the press and die type that the misplacement of the hand a fraction of an inch meant mutilation. The three accidents which the writer witnessed were exactly of this nature-two at soldering machines and one at a press and drill-in each case a hand was misplaced a fraction of an inch and came into contact with dangerous parts of the respective machines.

At mangles, too, the danger is grave. What the girls call "millionaire work"-work that has to come out straight-in contrast with "boarding-house" work, must be shoved up to within a quarter of an inch of the cylinder. Fingers once caught in such mangles are crushed. Consider

30 C. R. Henderson, op. cit., World To-Day, XIX, 972. 
in connection with these two points the high rate of speed at which the girls feed the work into the machine, and the precarious character of their work will be realized. ${ }^{33}$

From these facts it is evident that the slight slips and mistakes which every person makes are exactly the phenomena which precede many serious accidents when they occur in dangerous occupations. "When a cook drops a cup, the loss is a few cents; when a structural iron-worker is guilty of no greater inattention, he may lose his life."34

The thesis of this section has been confirmed by a report prepared by the Bureau of Labor which is not off the press at this writing (April I, I9II). The following excerpt is taken from proof sheets:

It (the fatigue process) gradually upsets those nice adjustments of the living organism upon which depend efficient labor and the safety of the worker. The margin of safety in modern industry is small. It is measured too frequently by fractions of an inch. Reduce the alertness and the exactness with which the body responds to the necessities of its labor, and by just so much have you increased the liability that the hand will be misplaced that fraction which means mutilation. ${ }^{25}$

Thus slight deviations entail serious consequences and result in industrial accidents. "The exhausted workman no longer has full control over his muscles. His results are less exact, danger by accident increases."36 Even the skilled laborer does not work as regularly as the machine. His ability to make accurate movements shows regularly returning shrinkings as a result of the activity of the neural-muscular factors. ${ }^{37}$ This phase of the fatigue problem has been summed up by Felix Arnold:

Concentrated activity, especially when it involves motor control, usually results in fatigue. There arises .... increased slowness of response. Efficiency of attention begins to decline. .... In simple reactions, the reaction time becomes longer. Objects in the field of attention persist for a less time in the center of control. On the subjective side, fatigue is felt as weariness, disinclination to persistent effort, sensation of strain in the muscles, lack of interest in situations which normally are of an impelling nature, and some-

33 Clark and Wyatt, McClure's, XXXVI, 402.

34 Bureau of Labor and Industrial Statistics (Wisconsin), r3th Bien. Report, Part I, p. 4.

${ }^{3 s}$ Senate Document No. 645, v. II, p. 42.

${ }^{36} \mathrm{H}$. Herkner, Handwörterb. d. Staatswissensch. (Jena, 1909), I, 1215.

${ }^{37}$ E. Roth, 14. Intern. Kongr.f. Hyg. u. Demog., II, 6I I. 
times as pain in the parts of the body affected. On the objective side fatigue is manifested by a general slackness and listlessness of the body posture, by relaxed fingers, and by asymmetrical and fidgety movements. Co-ordinations become more bungling, incorrect, and for finer control often impossible. ${ }^{23}$

If men and women subject to industrial overstrain are working at or near rapidly revolving knives or saws, are operating punches, presses, or drills at a furious rate of speed, their chances are good of being counted among the annual list. (in the United States) of 30,000 killed and 500,000 injured in industry. ${ }^{39}$

The law of fatigue as related to accidents and given at the close of Section II may be restated in the light of the facts of this section as follows: The irregularly increasing muscular in$x$ accuracy which accompanies work results in correlatively increasing chances of accident.

It is proposed to test this law by further facts. In the following section it will be attempted to verify further, if possible, the causal relationship existing between fatigue, decreasing muscular control, and accidents, by means of several series of controlled experiments in which various industrial conditions are more or less closely simulated.

\section{SOME CONTROLLED EXPERIMENTS}

(From the Psychological Laboratory of the University of Chicago) ${ }^{x}$

Section II set forth the fact that continued work is accompanied by increasing muscular inaccuracy. In Section III it was shown that these muscular inaccuracies are the immediate phenomena preceding a large proportion of accidents. In order to determine more exactly the nature of the muscular inaccuracies which increasingly accompany continued work and

${ }^{38}$ Felix Arnold, Attention and Interest (Macmillan, I910), I53.

"J. B. Andrews, "A Clinic for Industrial Diseases," Survey, XXV, 269.

" Preliminary to these experiments, the writer conducted two series of experiments on the typewriter. The striking of a typewriter key requires a definite muscular co-ordination. All variations of one-half inch and over from the correct muscle movement appear as errors on the typewritten pages. These faulty co-ordinations are similar in general nature to the muscular inaccuracies which precede many industrial accidents. The results of the typewriter experiments indicated clearly an irregular but marked increase in the number of muscular errors occurring during a given work-period. This increasing inaccuracy was accompanied by symptoms of increasing fatigue. But it will be observed that in experiments on the typewriter, the power which runs the typewriter is intrinsic; that is, the subject or operator by his own volition must keep the typewriter in motion. It appeared that these experiments would have 
which result in increasing danger of accident, a type of machine for experimental purposes was designed which in its operation would combine the factors most common to industrial conditions, namely, monotony, speed, mental strain-and which at the same time would permit a computation of the muscular inaccuracies resulting from operating it. ${ }^{2}$

Figs. I and 2 will give an idea of the apparatus used. The part of the machine designated $x$ in Fig. I appears in enlarged form in Fig. 2. The letters $a, b, c, d$ represent thin brass plates so set in the top of the table that their inner lines form a square of one-inch dimensions. They do not come in contact with each other; their upper surfaces are practically on a level with the upper surface of the table. The letters $a^{\prime}, b^{\prime}, c^{\prime}, d^{\prime}$ designate another set of brass strips whose inner lines are three-sixteenths of an inch from the inner lines of $a, b, c, d$, respectively. The subject was given wooden inch cubes, one side of each being covered with a thin brass plate. If the block was accurately placed its outer edges-brass side down-would exactly coincide with the inner lines of $a, b, c, d$. However, the outer edges of the brass base could extend over the lines of $a, b, c, d$ practically three-sixteenths of an inch in any direction and the placement would still be counted as accurate. But the brass strips were so electrically wired that $a$ and $a^{\prime}, b$ and $b^{\prime}$, etc., represented the termini of respective circuits. Hence if the brass base of a block for instance, was misplaced to the extent that one of its sides extended over $a^{\prime}$, as represented by the dotted line $r$, an electrical circuit was established and an error was recorded on an endless sheet of smoked paper carried by two slowly revolving Scripture drums, arranged after the manner of Yoakum. ${ }^{3}$ If the block

greater value if conducted on a machine which was run by external power, e.g., by an electric motor. In this case the operator would be required to keep up with the pace set by the machine, and not set his own pace.

It was this problem which I took to Professor James R. Angell, to whom I am indebted for making possible the experiments described in this section, for designing a considerable portion of the apparatus, and for many stimulating suggestions. The apparatus which is described in the following pages was built only after a special study had been made of dangerous machines in industry. It was designed especially to incorporate as many as possible of the general features of the machines used in the dangerous trades.

- For the purposes of this chapter, these experiments have been presented from a sociological point of view. Much material is at hand for a psychological discussion.

3 C. S. Yoakum, An Experimental Study of Fatigue, 54. 
was misplaced as represented by the dotted line $r^{\prime}$, the circuits represented by the termini $b$ and $b^{\prime}$, and $d$ and $d^{\prime}$ were closed respectively and two errors were recorded on the smoked paper

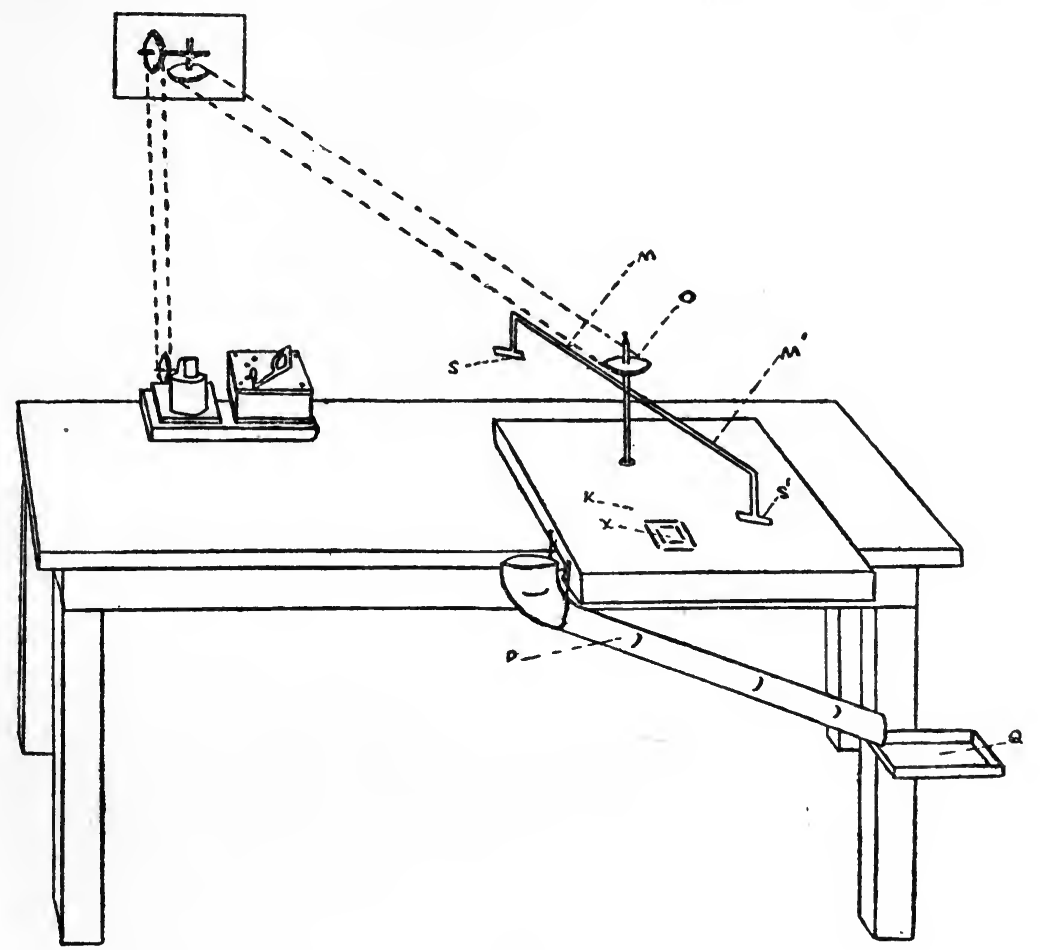

FIG. I

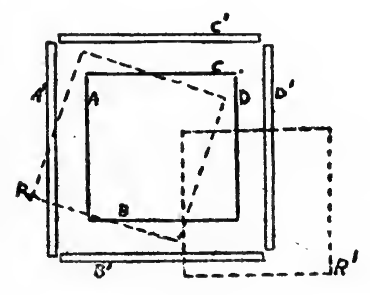

FIG. 2

by corresponding markers. It was not possible to close more than two circuits and hence make more than two errors by a single misplacement. It will be noted that the inner lines of $a^{\prime}$ 
and $d^{\prime}$, and of $b^{\prime}$ and $c^{\prime}$ are separated by one and three-eighths inches, respectively, so that a leeway of three-eighths of an inch in either direction was given.

A revolving pulley $O$ (Fig. I), driven by power obtained through a speed-reducer from a motor, carried a double arm, $m$ and $m^{\prime}$. Both $m$ and $m^{\prime}$ carried shields $s$ and $s^{\prime}$, respectively, set at an angle such that when the pulley revolved, the blocks being set on the square would be brushed off to the left and toward the subject who was seated facing $x$. Each of the shields $s$ and $s^{\prime}$ were of brass (as were the arms $m$ and $m^{\prime}$ and the pulley) and each carried a small brush of fine brass wire attached to the lower inner corner. As the shield brushed off a block at $x$ the small wire brush passed over a brass knob $k$ and closed an electrical circuit, which occurrence was recorded by a fifth marker on the smoked paper mentioned in the preceding paragraph. Reference to the smoked paper showed the nature of errors, i.e., the direction in which the misplacement occurred, the number of errors, and their occurrence in relation to the time-element. An observation method was devised which served as a check on the record carried by the smoked paper. Because of a great variety of phenomena which happened in connection with the placement of the blocks and which the registering apparatus could not be made to record, the observation method proved more accurate and satisfactory and was finally adopted.

Before each test the subject was given as much time as he wished for practice. He did not know exactly when his testperiod began nor when it was likely to close-except that he knew that it would not extend over twenty minutes. By this method the factors of "warming up," of the nervousness frequently attendant on beginning a piece of work, and of the "final spurt" were almost entirely eliminated. The actual test-period was made fifteen minutes long in all cases, although none of the subjects knew this fact-fifteen minutes being the length of time determined upon as sufficient to indicate many of the characteristics of fatigue, to show the tendency of these characteristics, and to bring out important points regarding the nature of muscular inaccuracies. The tests were made on successive days and 
at the same hour each day for the given subject as far as possible; any variations were noted. A record of the subject's general physical condition at the beginning of each test was kept and also of the subject's introspections at the close of the daily trial.

The following method of evaluation of errors was adopted as being the most satisfactory. If the block was misplaced to the left, for example, so as to establish the connection represented by the termini $a a^{\prime}$ (illustrated by the dotted square $r$, Fig. 2), one error was counted; if, as shown by the dotted square $r^{\prime}$, the block was misplaced so as to make the connections $b b^{\prime}$ and $d d^{\prime}$, two errors were recorded. If either hand of the subject was hit by the revolving shields $s$ and $s^{\prime}$, three errors were countedsuch an occurrence being a gross inaccuracy. Failure to put in a block-being the omission of a whole muscular co-ordinationwas evaluated at five errors. Other types of maladjustments occurred occasionally and were evaluated on the above basis.

It may be well to note that in these experiments an essential feature of the method is that stimuli were provided of the socalled extrinsic nature. ${ }^{4}$ The machine being driven by electricity set the pace and the subject was required to keep up. To the observer these tests appeared as a real contest between human muscle and sensitive nerves, and the machine, insensible and indefatigable. The machine regularly worked on and on; the subject worked irregularly, with increasing tendency to fall behind.

Although in these experiments no saws, knives, or drills were present and hence gross muscular inaccuracies did not mean actual mutilation of the subject's hands, this fact appeared to be adequately balanced by three other factors. (a) Throughout the experiments each subject clearly manifested an instinctive dread of getting hit by the revolving shield-even in the final experiments, the subject would instinctively jerk back his hand whenever he became conscious that his hand was likely to be hit. Throughout the experiments the records of each subject were posted and a healthy spirit of competition was maintained which assisted greatly in keeping up a maximum efficiency. (c) In particular, the graduated system of evaluating inaccurate coordinations served continually in keeping down the number of

'W. H. R. Rivers, The Influence of Alcohol, etc., on Fatigue, 12. 
gross inaccuracies. The writer believes that these factors when taken together served to maintain a degree of carefulness in operating this experimental machine comparable to that manifested by the average worker in the dangerous trades, who inevitably becomes inured to the danger of working close to revolving knives, saws, drills, etc.

Eleven subjects participated in these experiments. ${ }^{5}$ Br., $\mathrm{Hy}$., Pr., Sp., Sw., and Wr. were men; Ch., Fr., Hys., My., and Wd. were women. This list included trained psychologists who had worked at reaction-time experiments, at co-ordination of hand and eye movements, at general fatigue experiments. Three of the subjects had taken part in the prolonged series of fatigue experiments conducted by Yoakum. One of the subjects had worked in a screw room; another, as an operator in a telephone exchange. In view of the considerable amount of practice which was given in these experiments the results did not show any particular effects of the previous training of the subjects. This point will be discussed later. Further details regarding methods will be given when the various groups of experiments are described.

The first group of experiments was designed to get a maximum of simplicity of operation, of monotony, of speed, and of mental strain or unrelaxed tension. The rate was such as to require that a block be set on the square $x$ (Figs. I and 2) once a second or sixty times per minute. Two blocks were used. The cycle of a single operation may be described as follows: (a) stopping block I with the left hand when brushed off the square $x$ by the machine, and putting block 2 on the square $x$ with the right hand; (b) passing block I over from the left hand to the right hand; $(c)$ placing block I on the square with the right hand while the left hand stopped block 2 ; and so on. The monotony, speed, and unrelaxed tension of this process is obvious.

Eight subjects - four men, Hy., Pr., Sp., Sw., and four women, Ch., Fr., Hys., and Wd.--worked in Group I. Each subject was given several practice trials, covering two or three weeks, until the maximum efficiency was obtained, as far as could

s The writer wishes to express his deep obligation to the persons who willingly gave of their time and strength that this investigation might be furthered. 
be judged by the daily records of errors. The tests were then continued until six to ten normal records were obtained for each subject. By the use of volitional power and highly concentrated attention, and as a result of a strong spirit of rivalry, the subject tried in each test to make no errors or to keep the errors within minimum limits.

Among other things, the errors of each subject were tabulated according to their occurrence in the first or in the second half of the given test periods. ${ }^{6}$ The tabulated figures for each subject were added together and the average daily number of errors for the first and second halves of the test periods was obtained. The results appear in Table II.

TABLE II

Muscular Inaccuracies (Group I)

\begin{tabular}{|c|c|c|c|}
\hline Subject & $\begin{array}{l}\text { Average Num- } \\
\text { ber of Errors, } \\
\text { First Half }\end{array}$ & $\begin{array}{l}\text { Average Num- } \\
\text { ber of Errors, } \\
\text { Second Half }\end{array}$ & $\begin{array}{l}\text { Average Total } \\
\text { Number of } \\
\text { Errors }\end{array}$ \\
\hline 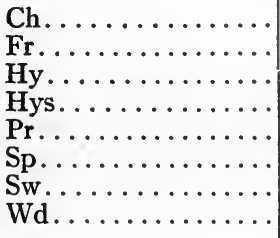 & $\begin{array}{l}3.00 \\
6.16 \\
6.66 \\
5.16 \\
2.00 \\
4.50 \\
1.83 \\
1.66\end{array}$ & $\begin{array}{r}6.00 \\
15.83 \\
12.00 \\
13.00 \\
5.83 \\
5.83 \\
4.00 \\
3.83\end{array}$ & $\begin{array}{r}9.00 \\
21.99 \\
18.66 \\
18.16 \\
7.83 \\
10.33 \\
5.83 \\
5.49\end{array}$ \\
\hline Total $\ldots . . . \ldots$ & 30.97 & 66.32 & 97.29 \\
\hline General average ... & 3.87 & 8.29 & I2.I6 \\
\hline
\end{tabular}

From Table II it will be observed that the average daily number of errors for all subjects was 3.87 for the first half of the test periods and 8.29 for the second half. In other words, 31.82 per cent of the errors occurred in the first half of the test periods and 68.I 7 per cent in the last half. As determined by the introspections, the immediate cause of the distribution of muscular inaccuracies in this fashion is to be found largely in the irregularly decreasing effectiveness of the attentive processes. In par-

'In analyzing the results of these experiments, a large number of tables have been made. Only those have been selected for use here which best present the general results. It is difficult to avoid the omission of some classifications of data which might prove helpful. 
ticular, such factors entered as rise of feelings of effort, of strains, of fatigue in the muscles of the eyes, arms, back, hands, legs, abdomen, etc. In many of the tests the subjects experienced a growing uncertainty of muscular control over the hands.

Whatever the cause, the most significant result of this group of experiments was the fact that the subjects were not able to maintain a steady degree of volitional attention even though they knew that the test would cover a short period of not over twenty minutes. During these tests the subjective processes broke down, in spite of continued efforts of the subjects to the contrary, to the extent of permitting practically twice as many errors to occur in the second half as in the first half of the work period. Some of the subjects, whose work in this group of experiments is fairly typical, are working for much longer test periods. The strain on the individual caused by the greater length of the work period is compensated by giving him a slower rate of speed. While full results are not yet at hand, the indications are that when the longer period is divided into two equal periods for purposes of comparisons, the relation between the number of errors occurring during the first half and during the second half of such a period is almost a duplicate of the results shown in Table II. In other words, when the operation of the experimental machine is made less rigorous and continued for greater lengths of time, so that fatigue does not develop in fifteen minutes (as in the experiments already described), but in the given increased period of time, it may be assumed that the results in Table II would not suffer material change.

Tables II and III illustrate the law of fatigue as given at the close of Section II, that continued work is accompanied by increasing muscular inaccuracy. Granted that the general results of this group of experiments would not have been essentially changed if a lower rate of speed had been substituted for a high rate and a longer period of time substituted for a short periodtwo substitutions which may be considered as counterbalancing each other in a large measure-then the following conclusion may be given: If the subjects in this series of experiments had been operating dangerous machines where slight misplacements 
mean mutilation, the danger of accidents would have been far greater (if not twice as great) in the latter half than in the first half of a given work period.

In Section II the point was emphasized that the increase in muscular inaccuracy which accompanies continued work depends on the rate of 'work. That is to say, if the operative of a dangerous machine should be "speeded up," his danger of suffering accident would be thereby increased; and that increased danger would persist as long as the increase in rate of work remained a "speeded-up" operation for the given operative. According to the law given at the close of Section II, an increase in speed will hasten the fatigue processes, the development of muscular inaccuracies, and hence the chances of accident.

In testing this point the apparatus used in the preceding series was slightly modified. A pipe $p$ and a square box $q$ containing a dozen inch cubes were added to the apparatus (see Fig. I). By this time the observation method had been so satisfactorily developed that the brass plates on one side of the blocks were taken off and the subject permitted to place the blocks with any side down. The cycle of operations consisted in catching the block with the left hand as it was brushed off the square $x$ by the machine and of dropping it in the opening of the spout $p$. In the mean time the right hand had to pick out another of the blocks from box $q$ and place it accurately on the square $x$.

The speed was made one-half that of the preceding series, or 30 blocks per minute. This was a rate which seemed slow or moderate to most of the subjects and errors appeared to occur more as a result of chance than from any other cause. As far as the speed was concerned, there was no excuse for errors. Tests were made daily at this rate until a series of records was secured sufficient to serve as a basis of comparison with the results obtained from speeding up. Then the rate was increased from 30 to $37 \mathrm{I} / 2$ blocks per minute. On the day that test I was made at the faster rate, and preceding the test, the subject was given all the time that he wished for practice. Tests at the $37 \mathrm{x} / 2$ rate were continued for twelve days for all subjects. Then a faster rate of 45 blocks per minute was offered. Table III gives 
the number of errors made by each subject during the series of trials at the three rates of speed.

TABLE III

Muscular Inaccuracies (Group II)

\begin{tabular}{|c|c|c|c|c|c|c|c|c|c|c|}
\hline Rate & $\begin{array}{l}\text { No. of } \\
\text { Trials }\end{array}$ & Br. & Fr. & Hy. & Hys. & My. & Pr. & Wd. & Wr. & Total \\
\hline \multirow{4}{*}{$30 . . .}$. & I & I & 2 & 2 & 4 & 4 & 0 & 6 & I6 & 35 \\
\hline & 2 & I & 6 & 8 & 2 & 5 & I & $\circ$ & 4 & 27 \\
\hline & 3 & 2 & 3 & 0 & 0 & 0 & I 2 & 6 & 9 & 32 \\
\hline & 4 & $\circ$ & I & 6 & $\mathbf{I}$ & 3 & 2 & I & I & I5 \\
\hline \multirow{11}{*}{$37 \frac{1}{2} \ldots<$} & I & 25 & 92 & 39 & I27 & I4 & 39 & 2 & 44 & 387 \\
\hline & 2 & I7 & 57 & I5 & 3 I & IO & 54 & 3 & 23 & 212 \\
\hline & 3 & $2 \mathrm{I}$ & I5 & I3 & I8 & I6 & I5 & 7 & 39 & I44 \\
\hline & 4 & IO & 5 & 29 & $6 I$ & I4 & 7 & 3 & 38 & 167 \\
\hline & 5 & 9 & 6 & I8 & 5 & 10 & 44 & 3 & 26 & II 7 \\
\hline & 6 & 9 & 23 & 3 & 20 & II & 23 & I & 18 & II 8 \\
\hline & 7 & 4 & I2 & 4 & I & 2 & 7 & 7 & I4 & $5^{I}$ \\
\hline & 8 & 3 & 29 & 2 & 4 & 7 & I7 & 3 & 6 & $8 \mathrm{I}$ \\
\hline & 9 & 3 & 23 & I & $3 \mathrm{I}$ & 4 & 34 & I & 6 & IO3 \\
\hline & IO & 3 & I & 7 & 6 & I & 2 & 6 & 7 & 33 \\
\hline & II & 3 & 22 & 22 & 4 & 0 & 8 & 7 & 4 & 70 \\
\hline & I 2 & 0 & 9 & 7 & 7 & $\circ$ & 7 & 7 & 33 & 70 \\
\hline \multirow{5}{*}{$45 \ldots \ldots$} & I & 48 & I 28 & 52 & 148 & $6_{5}$ & II5 & 70 & 325 & 943 \\
\hline & 2 & IOI & 108 & 18 & 166 & 56 & I34 & 56 & 88 & 736 \\
\hline & 3 & I23 & II 7 & 32 & 75 & 34 & IO4 & 64 & 202 & $75 \mathrm{I}$ \\
\hline & 4 & 57 & I82 & 75 & $2 \mathrm{I}$ & I3 & 102 & 26 & 108 & 584 \\
\hline & 5 & 46 & 79 & 82 & I34 & I5 & 118 & I6 & 256 & 746 \\
\hline
\end{tabular}

Although the first trials at the $37 \mathrm{r} / 2$ rate in the case of each subject were preceded by a practice period, the effect of speeding up from a 30 to a $37 \frac{1}{2}$ rate on muscular inaccuracy is marked. As indicated by Table III, the increase varies considerably from the case of Wd. to that of Hys., where the increase in number of inaccuracies is from $I$ to $I 27$. For the first six trials at the $37 \mathrm{I} / 2$ rate the process was clearly a speeded-up one for all the subjects excepting Wd.; a decrease in errors is also characteristic. For the last six trials at the $37 \mathrm{I} / 2$ rate, the totals of errors indicate that no further decrease in inaccuracies would have resulted if the series at this rate had been continued. The introspections given by the subjects bear out this conclusion. The totals for these last six trials also indicate that the $37 \% \frac{1}{2}$ rate had become a much less speeded-up process than for the first six trials at 
that rate, but that it still remained a speeded-up process when compared with the records for the 30 rate.

Table III shows that the introduction of the 45 rate (although the first trials were again preceded by a practice period) was accompanied by a large increase in the number of errors. Table IV is prepared from Table III and indicates the relative percentage of errors occurring in the first and second half of the trials at the 30 rate, for the first six and for the second six trials at the $371 / 2$ rate, and for the 45 rate, for each subject; at the 30 or slow rate where errors were not due to speed, but apparently to chance, the average percentages of errors indicate that practically the same number of inaccuracies occurred in the first half as in the second half of the given work period-the ratio being 50.0 to 49.8 .

But when the rate was increased to $37 \mathrm{~T} / 2$ blocks per minute there occurred not only a large increase in the actual number of errors, but, as will be seen by looking at Table IV, a large pro-

TABLE IV

Percentage of Errors (from Table III)

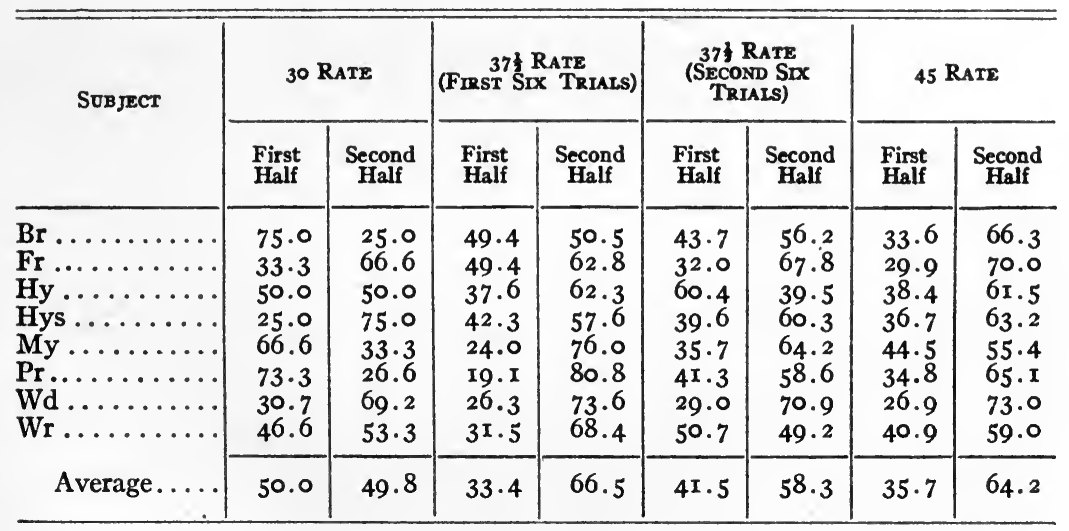

portion of the inaccuracies occurred in the second half of the given trials. The ratio of errors between the first and second halves of the first six trials at the $37 / 2$ rate was 33.4 to 66.5 . For the second six trials at the $37 \% 2$ rate when this rate no longer involved as speeded-up operations as during the first six tests, because of skill resulting from practice, the percentage of inac- 
curacies fell, the ratio being $4 \mathrm{I} .5$ to 58.8 . When the rate was increased to 45 blocks per minute, the process again became a speeded-up one and the percentage of inaccuracies in the last half of the trial periods again rose-this time to 64.2 per cent. The ratio was 35.7 to 64.2 .

The noteworthy fact in these experiments is that as soon as the work was speeded up from the 30 to the $37 \mathrm{r} / 2$ rate or from the $37 \% 2$ to the 45 rate, the larger part of the increase of errors took place in the latter half of the given work periods. These increases clearly show the effect of fatigue on muscular inaccuracies. This conclusion, based on the objective records, is corroborated by the introspections given by the subjects. While operating the machine at the speeded-up rates, all the subjects complained of sensations of fatigue during the second half of the work periods, ranging from distinct strains in the muscles of the eyes, arms, and hands to temporary paralysis of the right arm (Wr., in whose case the right arm co-ordinations broke down completely, and the subject was forced to stop in one test). Typical introspective reports are subjoined:

Eye strain felt during last three or four minutes.

Slammed blocks in toward close of period, because of less certainty of muscle control.

During last half of period eyes blurred continually.

Back began to ache about middle of period and continued.

Conscious of increasing inaccuracy and of increasing feeling of "losing out."

Greater tendency toward the last to fumble blocks.

Fumbling increased, caused by developing fatigue in fore-arm, and by lapses of attention.

Fatigue in arms felt early in trial.

Fagged all over-to keep up the process became a torture.

Felt pain between shoulders toward the last.

Almost decided that I couldn't keep it up for full period.

Compelled to exert increasing volitional power.

Strain in left arm toward the end of the period.

Increasingly tended to get behind in muscular movements.

Boredom of it increased.

Last few minutes seemed like hours.

Started well, but fatigue developed in arms, wrists, shoulders.

Terrible strain developed in right arm.

Became aware of a general inaccurate feeling in regard to hands. 
One or two other points brought out by this group of experiments may be mentioned here. Reference to the tables will make clear the fact of marked individual difference in regard to making errors. These variations do not appear to be explained when the subjects are classified on the men and women basis or according to the degree of psychological training, but rather by temperamental differences. Reference to the records of individual subjects (Table III) shows marked variations from day to day in many cases. The explanation for this fact appears to be found in the varying bodily conditions of the given subject from day to day. The decidedly abnormal conditions were of two kinds-either the subject found himself simply "out of form," or else he began the test normally and errors began to increase early and rapidly as a result of late hours, overwork, forms of illness.

The material presented in this section may be summarized at this point. These experiments indicate that uninterrupted work is accompanied by increasing muscular inaccuracy, and other things being equal, any speeding up in the operation of dangerous machinery means accelerated development of fatigue and of muscular inaccuracy. In other words, fatigue causes muscular inaccuracy. Since, as indicated in Section III of this study, men and women in the hazardous employments are working in close proximity to dangerous tools, and where misplacement of the hands a fraction of an inch means mutilation, the material presented in this section may be considered as evidence that fatigue causes accidents. The data presented in Section III to the effect that muscular inaccuracies are the actual phenomena preceding a large majority of accidents bears out the conclusion that fatigue, muscular inaccuracies, and industrial accidents are causally related. In the next section, the hours when accidents occur will be analyzed. 


\section{ACCIDENT-HOURS}

Reference is made in Section III to a study of accident records (State of Illinois for the year 1910) which has been made by the writer. It will be recalled that of the accident reports examined, 2,687 gave a fairly accurate description of what happened preceding the given accidents; and 2,203 or 82.2 per cent of the 2,687 accidents conceivably might have been avoided if the injured or the fellow-servant, who was the cause of the accident in some cases, had had accurate muscular control. Of the 2,203 accidents which might have been avoided, the time at which 2,162 of these occurred was given. These reports were tabulated according to the hours of the day, and the results appear in Table V. In general, there is a rise in the number of accidents during the forenoon, a decided fall after the noon period of rest, and another rise in the afternoon hours. Further conclusions must be withheld until certain factors are considered. A vital point is to be found, not in the number of accidents per hour, but in the number of accidents per hour during a period when the same number of employees are at work.

TABLE V

ACCIDENT-HouRs (ILLINOIS, I9IO)

\begin{tabular}{|c|c|c|c|c|}
\hline & Morning & Accidents & Afternoon & Accidents \\
\hline 7 to & $7: 59 \ldots \ldots \ldots$ & 79 & $I$ to $I: 59 \ldots$ & III \\
\hline 8 to & $8: 59 \ldots \ldots \ldots$ & I50 & 2 to $2: 59 \ldots \ldots \ldots$ & 156 \\
\hline 9 to & $9: 59 \ldots \ldots \ldots$ & I93 & 3 to $3: 59 \ldots \ldots \ldots$ & 227 \\
\hline Io to & 10:59....... & 246 & 4 to $4: 59 \ldots \ldots$ & 260 \\
\hline II to & II: $59 \ldots \ldots \ldots$ & 257 & 5 to $5: 59 \ldots \ldots \ldots$ & I45 \\
\hline I 2 to & $12: 59 \ldots \ldots \ldots$ & 49 & Other hours...... & 289 \\
\hline
\end{tabular}

The figures given in Table $\mathrm{V}$ represent factories in which the working hours are not similar. While in general the working day is from 7 A.M. to 6 P.M. with a rest period from I2 M. to I P.M. in the factories to which the statistics in Table $V$ apply, there are important variations. In many factories especially where women are employed, the day begins at 7:30 A.M. The time of the lunch period at noon varies-in one plant employing 
about 3,000 men and women, the writer found that practically one-half of this number take their lunch period from II :30 to 12. Frequently the employees begin their afternoon period of work at I2:45 P.M., and in some cities at I2:30 P.M. In the large cities the working day closes in a considerable number of cases at 5:30 P.M. or 5 P.M.; and if there is Saturday afternoon work, at 4 P.M. A study of the work-hours of the factories to which the figures in Table $\mathrm{V}$ apply shows that from 7 A.M. to 8 A.M., from II A.M. to I P.M., and after 5 P.M. a lesser number of employees are at work than during the other work-hours, when the employees of all the factories represented are considered in the aggregate. If the table shows a smaller number of accidents during the hour from 7 to 8 A.M. than in the succeeding hour, it is not safe to infer that the danger of accident is correspondingly less, since a smaller number of persons are at work from 7 to 8 A.M. than during the following hour. In Table $V$ the periods from 8 to II A.M. and from I to 5 P.M. are of almost uniform employment.

In considering this period of uniform employment the rate of work must be taken into account before definite conclusions may be drawn regarding the influence of fatigue. As pointed out in Section IV, the greater the speed of work, the greater is the danger of accident, and vice versa. Hence the question arises: Is the rate of work uniform in connection with dangerous machinery?

In a recent investigation by the United States Bureau of Labor, records were taken from hour to hour from stamping presses equipped with automatic counters for registering the production. Records were kept for twenty-three machines for periods varying from one day to seven. With reference to the results, the report of the Bureau of Labor says that it is extremely probable "that there is an average slackening of activity on the part of the workers in the last hour and a half of the day." 1 If this explanation be correct and be applied to the after-

"Quoted from proof-sheets of Vol. XI of the "Report on Condition of Woman and Child Wage-Earners in the United States," Senate Doc. No. 645, 6rst Cong., $2 \mathrm{~d}$ sess. 
noon period of uniform employment from $I$ to 5 P.M., it will be seen that the last hour from 4 to 5 P.M. is probably one during which the rate of activity is much less than during the preceding hours. In general and on the average it may be assumed that the afternoon period from I to 4 P.M., like the forenoon period from 8 to II A.M., is one of both uniform employment and of fairly uniform rapidity of work.

From each of the three-hour periods of both uniform employment and rapidity of work three other factors have been eliminated: (a) During the last half-hour of work before noon and before the time for closing there is likely to occur what is called the "final spurt," which comes with the realization that one's work is nearly finished and which tends to reduce the danger of accident because of the increased volitional forces brought to bear upon the work. (b) The close of the working period is to some extent a period of readjustment-accumulated work is removed; new stock is secured in order that the next period of activity may go forward unhindered. ${ }^{2}$ (c) There enters also the sense of accomplishment. The worker may proceed more leisurely to the close of the period, after he has accomplished a certain amount of work and has his task well in hand. ${ }^{3}$

The question arises: How do the afternoon totals compare with the forenoon totals? But an adequate basis of comparison is not present. In the first place, the forenoon period is often longer than the afternoon period. Further, it is not correct to compare the totals for the hours from I to 4 P.M. with those from 8 to II A.M. because the existence of a Saturday half-holiday during the summer, and in some trades throughout the year, depresses the afternoon totals, while a high number of accidents on Monday mornings after the Sunday holiday unduly increases the forenoon totals. Also/the evidence indicates that the rapidity of work is considerably lessened in the last hour and a half of the day's work and the chances of accident are correspondingly decreased.

= Op. cit., Senate Doc. No. 645, Vol. I, 395 .

'Ibid. 
Fig. 3 illustrates Table $\mathrm{V}$ and makes graphic the more or less regular increase in the number of accidents during both the forenoon and afternoon periods of uniform employment and of uniform speed of activity.) The fall in the number of accidents following the noon period of rest is striking. When it is recalled that Table $\mathrm{V}$ and Fig. 3 apply only to those accidents (Class B) which were immediately preceded by muscular inaccuracies of small proportion (see Section III), further illumination thus will be given to the law of fatigue as stated at the

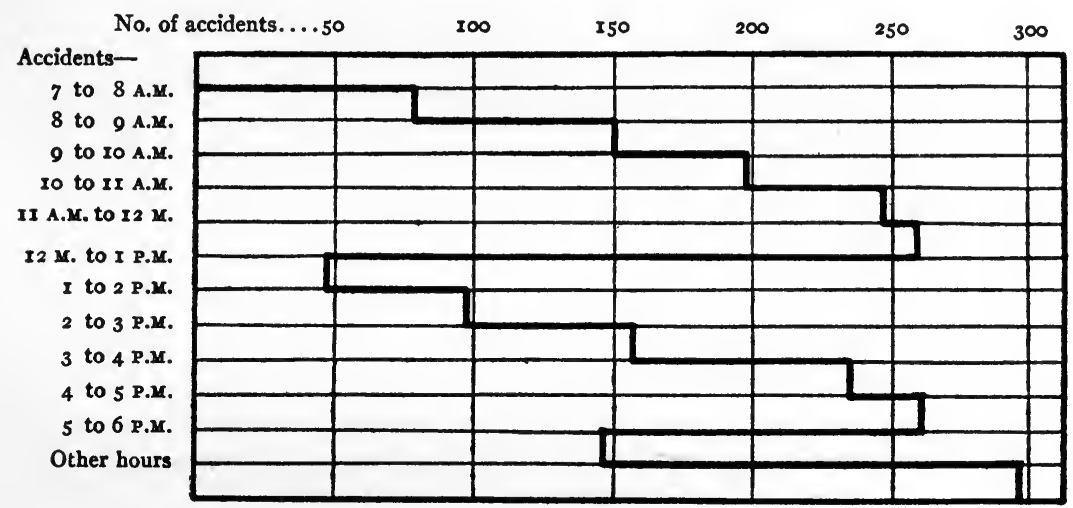

Frg. 3

close of Section III; namely, that (the increasing muscular inaccuracy accompanying uninterrupted work results in increasing numbers of accidents.)

The question of accident-hours has hardly been raised as yet in the United States. Only a few states, such as Wisconsin, Minnesota, and Illinois, require that the exact time of accidents be reported to the offices of factory inspection. At best, statistics of accident-hours in the United States are unsatisfactory. Table VI is prepared from the accident records of Wisconsin for the year 1907-8.4 It should be noted that in Table VI and in the tables of accident-hours which follow that all accidents are included-those due to the breaking of machinery, etc.; whereas in Table V (Illinois statistics) only those accidents are

'Bur. of Labor and Industr. Statis. (Wis.), r4th Biennial Report, Part I (r907-8), 78. 
classified which conceivably might have been avoided if the injured parties had had accurate muscular control. The question is raised by the compiler of the Wisconsin figures why the largest number of accidents did not occur in the last hour of work. Since many establishments close at some point between 5 and 6 P.M. the lessened number of accidents for this hour may be accounted for in this way in large measure. The explanation for the relative decrease in the number of accidents from II to I2 P.M. may be threefold: (a) As in Illinois, there may be whole shifts of men and women who take their lunch period at I I :30 A.M., and hence are not working during the last half-hour; $(b)$ There presumably is a slackening of the rate of work with a correlative decrease in danger of accident; (c) Some workmen with a surplus of energy may experience the "final spurt" and thus the danger of accident may be lessened.

\section{TABLE VI}

ACcident-Hours (Wisconsin, 1907-8)

\begin{tabular}{|c|c|c|c|c|}
\hline & Morning & Accidents & Afternoon & Accidents \\
\hline 7 to & $7: 59 \ldots \ldots$ & $x_{5} 6$ & $I$ to $x: 59 \ldots \ldots$ & 247 \\
\hline 8 to & $8: 59 \ldots \ldots$ & 244 & 2 to $2: 59 \ldots \ldots$ & 407 \\
\hline 9 to & $9: 59 \ldots \ldots$ & 427 & 3 to $3: 59 \ldots \ldots$ & 435 \\
\hline ro to & ro: $59 \ldots \ldots$. & 486 & 4 to $4: 59 \ldots \ldots$ & 446 \\
\hline I I to & II: $59 \ldots \ldots$ & 376 & 5 to $5: 59 \ldots \ldots$ & 277 \\
\hline
\end{tabular}

At all events, a consideration of the Wisconsin statistics for the hours of uniform employment and uniform rapidity from 8 to II A.M. and from I to 4 P.M. would eliminate many extraneous elements and justify the conclusion, as in the case of the Illinois statistics, that fatigue is a causal factor in accidents.

Table VII shows the distribution of accidents through the day in New England and southern cotton mills. ${ }^{5}$ The table includes figures from three series.

Of the three series presented, that of accidents in one New England mill for an eight-year period is the most significant, since it shows the comparatively unhindered operation of uniform causes. In this series the percentage of accidents gradually rises during the forenoon until il o'clock,

SOp. cit., Senate Doc. No. 645, Vol. I, 395. 
and then there is a decided drop. In the afternoon the percentage remains comparatively low until 4 o'clock, when there is a considerable rise followed by a large decrease in the percentage during the last hour of the day. . . . . The accident distribution is apparently a product of at least two factors. The worker in beginning gradually increases his speed, the result being a combination of increasing speed with growing fatigue. A basis is thus furnished for a growing accident rate. As already indicated, there is an increase in percentage of accidents both in morning and afternoon; but in the latter period the process is not repeated on the same scale as during the morning hours. The drop at the end of the period has several factors whirh vary from industry to industry. The fatigue is itself a large element in the result. It finally overcomes to a degree the driving energy which has kept up the speed."

TABLE VII

Accident-Hours (in Cotton Mills)

\begin{tabular}{|c|c|c|c|}
\hline Morning & Accidents & Afternoon & Accidents \\
\hline $7:$ or to $8 \ldots \ldots \ldots$ & I63 & $I: O r$ to $2 \ldots \ldots$ & I4I \\
\hline $8:$ or to $9 \ldots \ldots \ldots$ & 208 & $2:$ or to $3 \ldots \ldots \ldots$ & 165 \\
\hline $9:$ or to ro.......... & 251 & $3: 01$ to $4 \ldots \ldots$ & 203 \\
\hline ro:or to rr......... & 242 & $4:$ or to $5 \ldots \ldots \ldots$ & 147 \\
\hline Ir:or to I $2 \ldots \ldots \ldots$ & I 21 & $5:$ or to $6 \ldots \ldots$ & 92 \\
\hline
\end{tabular}

In presenting tables of accident-hours compiled from the records of nineteen establishments engaged in metal manufacture (a special inquiry made by the United States Department of Labor) and from the unpublished records of the Indiana department of factory inspection for two years, the Bureau of Labor says, by way of analysis of the figures:

It is evident that in the inter-relation of influences acting upon the situation now one and now another may be dominant. The most constant factor will be fatigue. It will be present in varying proportion in every case. It may act with the tendency to increase speed and thus to produce a greater number of accidents. It may in the end become so pronounced that speed is reduced and the accident rate lowered. (It should not be forgotten, however, that this lowered accident rate is presumably far higher than it would be were the laborer working at this reduced rate while yet unfatigued.)

There will be some tendency to minimize the factor of fatigue in the above process, because it is not a matter of acute sensation. It gradually upsets those nice adjustments of the living organism upon which depend efficient labor and the safety of the worker. .... Reduce the alertness and

' Ibid. 
the exactness with which the body responds to the necessities of its labor, and by just so much have you increased the liability that the hand will be misplaced that fraction of an inch which means mutilation.

The law of fatigue is a universal law. We may change its operation, but cannot eliminate the fact..... The weaker organism suffers soonest and most.

It may be well to note here the two methods of tabulating accidents according to hours. The unsatisfactoriness of both methods is due to the fact that accidents occurring from one to fifteen minutes before or after a given hour, say 8 A.M., are frequently reported as occurring at 8 A.M. In Table VII, accidents are tabulated from 7:0I to 8 A.M., etc., and accidents which really happen after eight o'clock and belong to the second hour are included in the record for the first hour of work. Thus to each hour-period of the day many accidents are accredited which really belong to the succeeding hour. Ten to eleven A.M. in Table VII, for instance, really means IO:I 5 to II :I 5 A.M. or thereabouts, and the greatest number of accidents really occurred somewhat later in both the forenoon and afternoon periods than is indicated.

On the other hand, in Tables V and VI accidents have been tabulated from 7 to 7.59 A.M., etc. This method is incorrect in the other direction. Some accidents occurring shortly before 8 A.M. and in the first hour of work have been reported as occurring at 8 A.M., and hence are included in the record for the second-hour period. In the succeeding ten tables both methods have been used, as far as the writer can determine. On the whole, it appears that the inaccuracies of the two sets of errors to a certain extent counterbalance each other.

The Minnesota Bureau of Labor has recently published a table giving a classification of hours of the accidents which were reported to the Bureau during the year August I, I909, to July $3 \mathrm{I}$, I9Io. In commenting on this table the Bureau says:8

Fatigue and nerve strain also have a place among the causes of accidents and the table and chart below (see Report) suggest that it may be an important place. The question should be given further consideration.

'Op. cit., Senate Doc. No. 645, Vol. I, 395.

- Bureau of Labor, etc. (Minn.), I2th Biennial Report (1909-10), 137, 140. 
The curves seem conclusive that .... fatigue largely explains the lapse of attention that causes injury in the later portion of the working period.

In the study of accident-hours, European countries, notably France and Germany, are far ahead of the United States. In France, a study of accident-hours has been made by Professor A. Imbert of the University of Montpelier. He found that a study of 5,534 accidents distributed among 140,407 workers in the circonscription de Toulouse gave results similar to those indicated by Table VIII. These statistics apply to wood-workers, the chemical industries, building trades, etc. Table VIII refers

TABLE VIII

ACCIDENT-Hours (France, r904)

\begin{tabular}{|c|c|c|c|}
\hline Morning & Accidents & Afternoon & Accidents \\
\hline 7 to $8 \ldots \ldots \ldots$ & 232 & I to $2 \ldots \ldots \ldots \ldots$ & 132 \\
\hline 8 to $9 \ldots \ldots \ldots$ & 305 & 2 to $3 \ldots \ldots \ldots$ & 3 ro \\
\hline 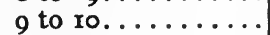 & 340 & 3 to $4 \ldots \ldots \ldots \ldots$ & $42 \mathrm{I}$ \\
\hline ro to $\mathrm{rr} \ldots \ldots \ldots \ldots$ & 478 & 4 to $5 \ldots \ldots \ldots \ldots$ & $5 \times 3$ \\
\hline Ir to $12 \ldots \ldots \ldots \ldots$ & 292 & 5 to $6 \ldots \ldots \ldots$ & 254 \\
\hline
\end{tabular}

to the year 1904, represents all industries, and covers the departments of Herault, Aveyron, Lozere, Cantal, and Tarn. ${ }^{9}$ Imbert interprets these figures as follows:

A large number of accidents result directly from the physical or mental fatigue of the workmen at the moment of the accident and this assertion can easily be proved by innumerable instances..... One result .... is that fatigue renders the workman less apt to avoid accident since he cannot make ("ne peut plus réaliser") as intense an effort as usual nor execute movements of his normal rapidity. .... Two facts are shown very clearly by this table of figures (see Table VIII); namely, the considerable share played by fatigue in producing accidents and the equally important influence, in the inverse sense, of the midday hour of rest. ${ }^{10}$

Fatigue being the inevitable consequence of work, accidents inexorably increase from hour to hour."

Imbert refers to the inquiries made by M. Le Roy, division factory inspector of Toulouse, for the years 1903 and 1904, and says that the results, which apply to several thousands of acci-

'A. Imbert and M. Mestre, "Nouvelles statistiques d'accidents du travail," Rev. Scientifique, October 2I, I905, 52I.

${ }^{\prime 0}$ A. Imbert, "Les accidents du travail et les compagnies d'assurances," Rev. Scientifique, June 4, 1904, 715.

${ }^{\text {" }}$ See Footnote 7. 
dents, are in harmony with his results ("toutes, sans exception, presentent les caractères généraux que nous avons énuméré cidessus"). An excerpt from M. Le Roy's analysis is subjoined.

It is indisputable, in fact, that the more fatigued a worker is, the more liable he is to accident. The accident is then the consequence of the combined results of physical depression, relaxed attention, and less rapid movements..... All these data and the various statistics to which reference has been made bring us necessarily to a consideration of fatigue as one of the chief causes of accidents. . . . This cerebral fatigue, due to monotonous, speeded-up labor, induces a nervous depression which is betrayed by inattention, very often resulting in accident. It is precisely this form of fatigue that explains the increasing progression of accidents with the progress of working hours in industries where work is most often limited to watching machinery. ${ }^{12}$

Germany was among the first nations to require that accidenthours be reported. Table IX is compiled from the German accident statistics for the years I887 and I89I, and applies to all of the various trades and to agriculture combined. The accidents represented in Table IX appear to have been reported with more system than that shown in the reporting of accident-hours in other countries, with the possible exception of France. Table IX represents a wide and comprehensive range of accidents. ${ }^{13}$

TABLE IX

ACCIDENT-Hours (Germany, r887, r89r)

\begin{tabular}{|c|c|c|c|}
\hline Morning & Accidents & Afternoon & Accidents \\
\hline 7 to $8 \ldots \ldots \ldots$ & $\mathrm{I}, 54 \mathrm{I}$ & $I$ to $2 \ldots \ldots \ldots$ & 1,727 \\
\hline 8 to $9 \ldots \ldots \ldots$ & $\mathbf{I , 9 6 1}$ & 2 to $3 \ldots \ldots$ & 2,445 \\
\hline 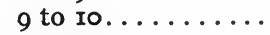 & 2,490 & 3 to $4 \ldots \ldots \ldots$ & 3,229 \\
\hline Io to $11 \ldots \ldots \ldots$ & 3,455 & 4 to $5, \ldots \ldots$ & 3,194 \\
\hline II to I $2 \ldots \ldots \ldots$ & 3,213 & 5 to $6 \ldots \ldots \ldots$ & 2,824 \\
\hline
\end{tabular}

The results of the investigations made in Germany in the years 1897 and 1907 are similar in the main to those given in Table IX. ${ }^{14}$ Of the 81,284 accident cases reported for the year

"See Brandeis and Goldmark, Ten-Hour Law for Women (New York), 24r, 242.

${ }^{3}$ See E. R. Krejcsi, 80 Cong. Intern. d'Hyg. et de Demog., VII,328; also the 24th Anmual Report, Commissioner of Labor (U.S.), Vol. I, I132-34; also the I7th Annual Report, New York Bureau of Labor Statistics, 730-939.

${ }^{14}$ See Amtliche Nachrichten des Reichs-Versicherungsamts, Beiheft I, Teil I (1910); also see Bulletin of the Bureau of Labor, No. 92 (January, rgrr). It should be noted that these German statistics refer to fatal accidents and to those cases where the injured was disabled for more than thirteen weeks. They include the accident reports from the mining, quarrying, iron-and-steel, metal-working, textile, wood-working industries and from the building trades. 
I907, I3.87 per cent occurred between the hours of 6 and 9 A.M., and 28.42 per cent between the hours of 9 A.M. and I 2 M.; while I3.8I per cent happened between the hours of 12 and 3 P.M., and 26.32 per cent between the hours of 3 and 6 P.M. In regard to the 45,97I accident cases reported for the year I897, the percentages of the accidents for the different sections of the day run approximately parallel with those given for the year 1907 . For both years the increase in the number of accidents during the forenoon and afternoon periods is most pronounced in the metal-working trades. The percentages for the 424 accident cases reported in 1907 for the South German metal-workers were as follows: 12.89 per cent for the hours from 6 to 9 A.M., and 37.23 per cent for the hours from 9 A.M. to I 2 M., and II.93 per cent for the hours from I 2 M. to 3 P.M., and 32.22 per cent for the hours from 3 to 6 P.M.

In England little attention has been given to accident-hours; a partial and inadequate list of accidents in factories and workshops for the year 1903 may be found in the British Sessional Papers, House of Lords. ${ }^{15}$ Table $\mathrm{X}$ gives the figures of a recent study of accident-hours in Belgium (1907) and applies to all industries. ${ }^{16}$

TABLE X

Accident-Hours (Belgium, 1907).

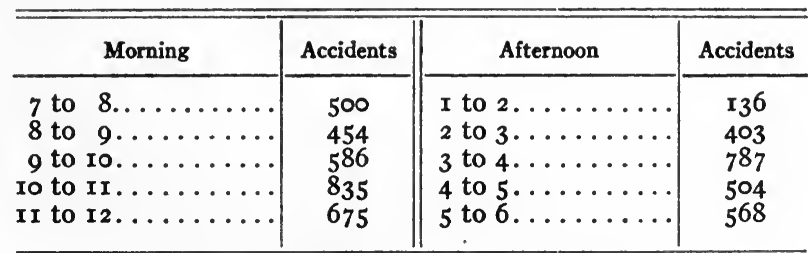

In Copenhagen, Dr. H. Bille-Top kept a record for ten years ( 1898 to 1907 ) of the industrial-accident cases which he was called upon to attend-according to the hour of their occurence. ${ }^{17}$ Dr. Bille-Top attributes the increase in the number of

${ }^{25}$ Vol. LIX, 2 Ir.

"Ministère de l'industrie et du travail, Rapports annuels de l'inspection du travail (1907), 212, 213.

"H. Bille-Top, "Die Verteilung der Unglücksfälle der Arbeiten, die Wochentage und die Tagesstunden," Centralbl. f. Allegemein. Gesundheitspfl., XXVII, 197. 
accidents in both the forenoon and afternoon periods to increasing fatigue ("zunehmender Müdigkeit, zunehmender Abgespanntheit").

Professor G. Pieraccini and Dr. R. Maffei, head physicians in the Royal Main Hospital, Florence, have made an investigation of the accidents (with reference to accident-hours) which took place in some of the railway machine-shops of Italy (I9OI to 1905). The results of their tabulation of accident-hours are given in Table XI. They omit the first hour of work of both

TABLE XI

Accident-Hours (ItALY)

\begin{tabular}{|c|c|}
\hline Hours of Work & Accidents \\
\hline 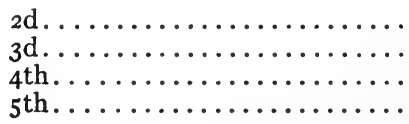 & $\begin{array}{l}206 \frac{1}{2} \\
25^{8} \\
324^{\frac{1}{2}} \\
323\end{array}$ \\
\hline
\end{tabular}

periods of the day-because fewer workmen are at work than during the succeeding hours. The accidents for the corresponding hours of the forenoon and afternoon periods are added together. Professor Pieraccini concludes that the protraction of the hours of labor raises the number of accidents with each successive hour, in both the first and second half of the day. ${ }^{18}$

In Vienna, Dr. Leo Verkauf has made some investigation of accident-time in connection with insurance studies. His figures refer to those industries (in Austria) in which a short recess, sometimes of thirty minutes, is given at IO A.M. and at 4 P.M. ${ }^{19}$ They show an increase in the number of accidents for the first three hours of the forenoon and of the afternoon periods. Without some sort of comparative basis covering the same industries, the effects of the recess are difficult to determine.

Many conditions in Europe are different from those in the United States. Yet the fact that European investigations are uniformly emphatic in the assertion that the danger of accident increases with continued work is most significant for the American situation. The fatigue effects of the great and feverish haste

"See Brandeis and Goldmark, op. cit., 252.

"E. R. Krejcsi, op. cit., 328. 
at which things are done in the United States must be added to the regular fatigue effects of the more deliberate European methods of operation.

Table XII gives the statistics to which reference has been made in the preceding paragraphs. The totals appear at the bottom of the table. From these figures it is not possible to make a comparison of the number of accidents occurring in the forenoon with those of the afternoon because the Saturday and other half-holidays depress the afternoon totals and because the forenoon period is frequently of greater length than the afternoon period. No attempt has been made to tabulate accidents

TABLE XII

SUMMARY OF ACCIDENT-HourS

\begin{tabular}{|c|c|c|c|c|c|c|c|c|c|c|c|}
\hline Hours & 7 to 8 & 8 to 9 & 9 to $x$ & rotory & II tor 2 & 12 to $I$ & $x$ to 2 & 2 to 3 & 3 to 4 & 4 to 5 & 5 to 6 \\
\hline li & 97 & 150 & I93 & 246 & 257 & 49 & III & 156 & 227 & 260 & I 45 \\
\hline $\begin{array}{l}\text { Wisc } \\
\text { U.S. }\end{array}$ & I56 & 244 & & 486 & 376 & 94 & 247 & 407 & 435 & 446 & 277 \\
\hline & I63 & 208 & $25 \mathrm{I}$ & 242 & I 2 I & 67 & I4I & I65 & 203 & I47 & $9^{2}$ \\
\hline$\frac{6 i}{}$ & 380 & $\begin{array}{l}538 \\
\end{array}$ & 653 & 573 & 226 & 233 & 439 & 634 & 590 & $4 \pi 2$ & I59 \\
\hline Indis & 818 & 1,072 & $\mathbf{I}, 3^{32}$ & $\mathbf{I}, \mathbf{I} 37$ & 765 & 368 & 943 & $I, 054$ & I,I99 & 899 & 353 \\
\hline Fra & 25 & 30 & 20 & 57 & 63 & $\ldots$ & 18 & 40 & 45 & 105 & II8 \\
\hline $\begin{array}{l}\text { (forrgo4) } \\
\text { ny (for }\end{array}$ & 232 & 305 & 340 & 478 & 292 & 50 & I32 & 310 & $42 I$ & 513 & 254 \\
\hline & 794 & $8 I_{5}$ & 1,069 & $\mathrm{I}, 598$ & $\mathrm{I}, 590$ & 587 & 745 & 1,037 & I, 243 & $\mathrm{I}, \mathrm{I} 78$ & 1,306 \\
\hline & 747 & $\mathrm{I}, \mathrm{I} 46$ & $I, 42 I$ & $I, 857$ & 1,623 & 738 & 982 & $\mathrm{I}, 408$ & 1,986 & 2,016 & 1,518 \\
\hline & 500 & 454 & 586 & 835 & 675 & 74 & 136 & 403 & 787 & 504 & 568 \\
\hline Eng & 9 & 19 & 18 & 27 & 46 & 23 & II & I8 & 22 & 24 & 24 \\
\hline Denmark & II & I 2 & I6 & 20 & 34 & 5 & 9 & I4 & 26 & 29 & 20 \\
\hline Total & 3,732 & 4,993 & 6,326 & 7,566 & 7,068 & 2,289 & $3,9 I_{4}$ & 5,646 & 7,184 & 6,533 & 4,834 \\
\hline
\end{tabular}

according to the days of the week. Not only are there insufficient statistics to be tabulated in this way, but the Sunday period of supposed rest introduces new and complex factors. The records for the day following pay-nights indicate that abnormal factors have entered. As far as accident records go which may be tabulated by the days of the week, they indicate a large number of accidents on Monday, a much less number on Tuesday, a gradual rise till the close of the week, when the number of accidents on Monday is exceeded. "In many industries, notably the iron and steel, mining, textile, and railway, the 
number of accidents steadily increases from the first or middle of the week and attains a maximum for Saturdays."20 Sunday recreation seems to unfit workmen for steady work on Monday, "but fatigue evidently plays a rôle also; for even on Monday the number of accidents between 9 A.M and $12 \mathrm{M}$. is larger than between 6 and 9 A.M., even in proportion to the hours worked in the two periods."

Table XII gives the same general results as Table V (Illinois statistics): (a) A marked increase of accidents during the forenoon period; $(b)$ A decided fall after the noon period; and ( $c$ ) Another marked rise in the afternoon period. Accurate conclusions regarding fatigue effects must be confined to those workhours when the number actually at work is uniform and when the rapidity of work is fairly uniform. The hours of uniform employment and of uniform rapidity of work as determined in the early portion of this section, are from 8 to II A.M. and from I to 4 P.M. On the basis of this analysis, Table XIII has been constructed; the figures have been taken from Table XII. The number of accidents for the first hour of the three-hour morning

TABLE XIII

Accident-Hours (Final Results)

\begin{tabular}{|c|c|c|c|}
\hline & FIRST HoUR & SECOND HouR & Trird Hour \\
\hline & $\begin{array}{l}8 \text { to } 9 \text { Morning } \\
\text { I to } 2 \text { Afternoon }\end{array}$ & $\begin{array}{l}9 \text { to ro Morning } \\
2 \text { to } 3 \text { Afternoon }\end{array}$ & $\begin{array}{l}\text { so to } x \text { Morning } \\
3 \text { to } 4 \text { Afternoon }\end{array}$ \\
\hline 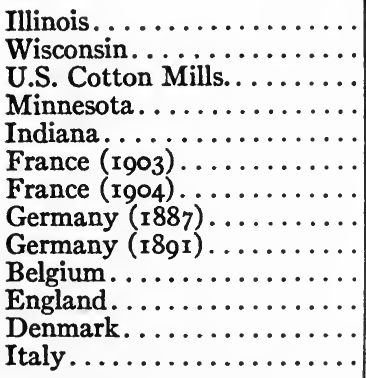 & $\begin{array}{r}261 \\
491 \\
349 \\
977 \\
2,015 \\
48 \\
437 \\
1,560 \\
2,128 \\
590 \\
30 \\
21 \\
206\end{array}$ & $\begin{array}{r}349 \\
834 \\
416 \\
\mathbf{1}, 287 \\
2,386 \\
60 \\
650 \\
2,106 \\
2,829 \\
989 \\
36 \\
30 \\
258\end{array}$ & $\begin{array}{r}473 \\
921 \\
445 \\
\mathbf{1}, 163 \\
2,336 \\
102 \\
699 \\
2,841 \\
3,843 \\
\mathbf{1}, 622 \\
49 \\
46 \\
324\end{array}$ \\
\hline 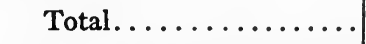 & $9, \mathrm{I}$ I3 & 12,230 & 15,064 \\
\hline
\end{tabular}

• Bureau of Labor Statistics (New York), XVII, 786. 
period of uniform employment and rapidity has been added to the number of accidents for the first hour of the afternoon period of uniform employment and rapidity, and so on. The more or less regular increase in the number of accidents, hour by hour, from $9, \operatorname{II} 3$ to 12,230 and from $I 2,230$ to $I 5,064$, indicates quite definitely the results of fatigue in terms of actual accidentsinasmuch as extraneous elements have been largely accounted for and not included in these figures.

Table XIII serves as a basis for the following conclusion: Continuous work, other things being equal, is accompanied, hour by hour, by an increasing number of accidents. Table XIII adds weight to the statement of the law of fatigue given at the close of Section III; the increasing muscular inaccuracy which accompanies uninterrupted work results in increasing danger of accident. Table XIII is offered in support of the thesis of this investigation, that fatigue is a cause of industrial accidents.

In the following section an attempt will be made to answer the question, Has fatigue attracted attention to itself to the extent that it has been indicted as a cause of accidents by men of judicial and conservative mind?

\section{JUDICIAL FINDINGS AND DECISIONS}

The accident statistics presented in the preceding section were related mainly to the development of fatigue and to the increase of accidents during the regular ten-hour day. The figures for accidents occurring during overtime work are very inadequate. Light is thrown on this point from two important sources: (a) the reports of the Interstate Commerce Commission, and $(b)$ the decisions of the courts. Although the material used in this chapter and gleaned from these two sources is largely incidental to the main function of these sources, it is for that reason of special value for this investigation. The overtime accident cases cited in this section are not intended to show the relative danger of working "overtime," since there is no adequate basis of comparison. The accident cases cited here are those apparently due to fatigue of overwork and per se are offered as additional evidence in defense of the thesis that fatigue 
is a cause of accidents. No attempt has been made here to offer an exhaustive list of such cases. The purpose at this point is to cite cases which will establish the fact, not the quantitative extent, of fatigue resulting from working overtime as a cause of accidents.

For several years past the Interstate Commerce Commission has concerned itself with a study of railway accidents; its findings are published quarterly. An excerpt germane to this investigation follows:

In nearly or quite every bulletin that has been issued, it has been necessary to record one or more collisions due to the mistakes or negligence of men who have been on duty so many hours as to raise the supposition, if not the presumption, that they had become drowsy, if they had not actually fallen asleep; and cases in which enginemen are definitely reported as being asleep on duty are common. ${ }^{1}$

Table XIV presents a list of fifty-four railway accidents compiled from the reports of the Interstate Commerce Commission. In these cases, the person or persons responsible for the accident had been on duty periods of time varying from eleven hours and nineteen minutes to thirty-nine hours and twenty-five minutes without intermission (except where noted). ${ }^{2}$ In respect to the accidents tabulated, the Interstate Commerce Commission either states or directly implies that "the men at fault had been on duty an excessive number of hours." 3 The implication is clear that the fatigue of overtime work was the chief cause of these accidents involving loss of life and property. The facts upon which Table $\mathrm{XIV}$ is based are submitted as proof from an angle different from that of the preceding chapters that fatigue is a cause of accidents. Typical illustrations of what happened directly previous to the occurrence of the given accidents are given:

Accident No. 8 (Table XIV). Flagman, who had been ordered to hold one of the trains, went into caboose to get red light; sat down to warm himself and dry his clothes; fell asleep; had been on duty sixteen and a half hours.

'Interstate Commerce Commission, Report, No. 18, ro.

- The size of Table XIV is such that limitations of space do not permit its publication. Its contents, however, are indicated here.

${ }^{3}$ See Footnote r. 
Accident No. 30. Due to forgetfulness on the part of an engineman 2I years old who had been on duty thirty-nine hours and twenty-five minutes. Accident No. 34. Operator fell asleep and failed to deliver meeting order; on duty twenty-four hours.

Accident No. 38. Engineman fell asleep and slept two minutes; had been on duty twenty-one hours.

Accident No. 32. (Forty-two killed and injured.) Operator turned east-bound passenger train on wrong delivery track. ... . He had been on duty twenty hours and fifty minutes.

Accident No. 40. Engineman fell asleep and passed automatic block signal set against him; also passed flagman; had been on duty seventeen hours.

Accident No. 4I. Engineman (killed) disregarded flag; had been on duty twenty-eight hours.

Accident No. 46. (Fifty-six killed and injured.) Misplaced switch at meeting point. Brakeman had been on duty twenty hours and forty minutes.

Accident No. 53. (Eight killed and injured.) The conductor and flagman of the freight had been on duty sixteen hours and fifty minutes. The freight was delayed .... the flagman was left at " $D$ " to stop the northbound train..... After remaining at this station about seven hours (the flagman) was sitting on the steps of a caboose of a freight train standing on the side track, with the lantern on one of the lower steps of the caboose between his feet. While so sitting he fell asleep and was not roused until the north-bound train came along and passed him (and ran into the delayed freight).

Table XIV includes fifty-four collisions and derailments in which the total number of killed and injured was five hundred and forty-one persons; the total damage to engines, cars, and roadbed was $\$ 512,453$. When the Interstate Commerce Commission gives as the chief cause in each of these instances the fact that the men at fault had been on duty an excessive number of hours, and when the circumstances preceding the given accidents are considered, the proof is strong that the fatigue of overwork was beyond doubt the causal factor. Table XIV presents fifty-four concrete, important cases in support of the proposition that fatigue is a cause of accidents.

Further testimony in defense of the thesis of this treatise has been obtained from decisions of the courts-this is presented in the paragraphs which follow. Seven cases will be cited here in which the courts have decided that fatigue was a cause of the given accidents. 
(a) In the case of Pennsylvania v. McCaffrey, the Supreme Court of the State of Indiana held:

Unless it be that a master has a right to require a servant to stand at his post of duty without food or rest for nineteen hours every day, Sundays included, and that such conduct is not a breach of duty to the public as well as to its other servants, it follows that the appellant (the railway company) in this case has not performed its duty towards decedent without which it is liable if this negligence was the proximate cause of his accident. That it was, it is clear. The law of nature is inexorable in its demands. The cravings of hunger must be appeased. The laws of humanity declare that every man fit to be a member of a train crew must have three meals, some rest, and eight hours sleep a day. The appellee well says: "Deprived of these requisites of intelligent life, a soldier becomes a coward; a workingman a drone." Any being would lose his strength if worked a few months by the time schedule provided for this crew. Every statute and employers' rule is made in the presence of, and subject to the laws of nature. Hunger, thirst, and sleep are imperative; and when a schedule is made of nineteen consecutive hours of service on a train, and no provision is made by the company for their supply of food, it is understood that the employees must, of necessity, at times during the service, leave their places to get their meals. So that when the engineer and conductor left the train, after thirteen hours' service, on the day of the accident, to get their suppers it was in obedience to this law of nature-an over-ruling necessity, and was not, therefore, negligence on their part. They were not deserters, and their conduct cannot be characterized as offending habits."

(b) In the case of Galveston, H. \& S.A. Ry. Co. v. Brozen et al., the Court of Civic Appeals of Texas said:

In determining the question of Brown's negligence in going to sleep on his engine, the jury could consider a fact in evidence, viz., that he had been working for appellant for the five days and nights preceding this accident, and was overworked to such an extent that sleep was unavoidable. We think that when appellant so overworks one of its employees that he cannot be expected to stay awake, it ought not to be allowed to say that he was negligent in going to sleep, in a question affecting the observance of its rules.

(c) The Supreme Court of the State of Indiana has handed down a decision of special importance in the case of the Republic Iron \& Steel Co. v. Ohlet. Excerpts from this decision are given herewith.

At the time the plaintiff sustained the injury alleged, he had been working continuously, at the instance and request of the defendant, in the said factory, for a period of forty-eight hours, without any sleep; and when he was ordered by said foreman to hold the rod, by reason of his continuous

4 38 N.E. Reporter, 67.

${ }^{5} 59$ S.E. Reporter, 930. 
work, without sleep, he did not realize or appreciate the danger to which he was being subjected. .... It is disclosed that after he had worked continuously some thirty-six hours in turning the rod, he informed Kelly, the foreman, that he did not believe he could endure the labor any longer; but the latter informed him that he must continue at work until the rod was finished. It is not reasonable to assert that a man who has labored continuously for a period of forty-eight hours without sleep, or for even a much shorter time, is in his normal condition, or that he under the circumstances can properly exercise all of the faculties or senses with which he is endowed. .... A human being deprived of sleep for the period which appellee was becomes dull in intellect and apprehension, and necessarily must be more or less unmindful of his surroundings. .... The jury had the right at least to consider this feature of the case, as bearing upon the question whether, under all of the circumstances, appellee apprehended and appreciated the danger to which he was subjected."

(d) In the case of Pelin v. New York Centr. and H.R.R. Co., the Supreme Court of New York, Appellate Division, Fourth Department, reversed the trial court's decision in favor of the defendant and held that there was sufficient evidence to warrant the jury in finding that the injuries were due to exhaustion of certain servants of the corporation, owing to their having been on duty twenty-four consecutive hours (in violation of the statute). The court also held that, although those directing the movements of a train-crew might reasonably have anticipated that the run on which the crew was engaged would not last twenty-four consecutive hours, the conditions of the business of the road having been such that the run could not be completed in less than such time, and an injury having resulted from the exhaustion of the crew owing to the hours of work, the corporation was liable. Says the court:

The statute is for protection of employees liable to be injured by the carelessness or oversight of co-employees, caused by exhaustion induced by long-continued application to work..... A railroad company with a crew out on a train for more than twenty-four hours may elect to have the trip completed by the same crew. If so it runs the risk of liability for any injuries sustained by any of its co-employees, and which is the proximate cause of exhaustion or inattention caused by such working overtime..... The jury had a right to say that the fact that the flagman was asleep was due to over-exhaustion by reason of his protracted employment, and that the collision might not have occurred had he been in his normal wakeful condition. ${ }^{\text {T }}$

'68 N.E. Reporter, 90r.

'N.Y. Supp., No. 92, 468. 
(e) The case of the Great Northern Railway v. Couture, who was injured while engaged as a brakeman, is directly to the point. "The decision in the reported case is a novel one, and there are but few decisions upon the liability of a master for injuries caused by compelling him to work an excessive number of hours."

A master who keeps his servant continuously at work for an undue number of hours is liable in damages for an injury which the servant sustains in the ordinary discharge of his duty, in consequence of his inability, from fatigue and exhaustion, to use the requisite skill and care. [The company was held liable] not upon alleged grounds of having used a defective system of coupling, nor for an excessive rate of speed in bringing the cars together, but for keeping the young man at work for an unreasonable length of time without sleep. .... It could not be otherwise than that his bodily strength was at that time exhausted and that his mental faculties must have been rendered dull and his power of observation greatly weakened. . . . The learned judge was right in holding the present appellants responsible .... in the application of the well-known principle that the employer's care for his workmen must be proportional to the risk of the occupation in which he engages them. To exact the extra-hazardous risk of coupling the cars in this instance required a degree of supervision and care on the part of the railway company's officials, which they greatly neglected, in compelling Couture to perform that work at three o'clock in the morning, after a service of forty-eight hours, interrupted only by two breaks, one of six and one of two hours. We have no hesitation in adopting the learned trial-judge's conclusion in this respect, and we believe this considerant of his judgment was sufficiently warranted by the terms of the plaintiff's declaration.

(f) In affirming the decision of a lower court in favor of L. W. Reed, administrator, in the case of Reed v. Southern Railway Co., the court states:

The testimony tended to show that Reed had mistaken the time by reason of the fact that his watch had run down; but it likewise tended to show that this was caused by the defendant in requiring or permitting Reed to operate his engine for forty-two consecutive hours immediately preceding the collision, without rest, and for twenty-seven or twenty-eight hours without anything to eat. This was evidence of negligence [on the part of the Southern Railway Co.]. ${ }^{10}$

(g) E. D. McCrary, a flagman in the employ of the Southern Railway Company, while lying on the outside of the tracks

\footnotetext{
${ }^{8} 7$ Amer. and Eng. Annotated Cases, I90. 'Ibid. $\quad{ }^{20} 55$ S.E. Reporter, 2 I8.
} 
(August 17, 1906) near Sheldon, S.C., presumably asleep, with his shoulders between the cross-ties and his head or a part of it on the rail, was killed by a passing freight. In the trial in the circuit court, the Southern Railway Company was charged with careless negligence

in requiring and permitting the said E. D. McCrary to act as flagman upon said train, and to go out as flagman on the trip upon which he was killed, when the said company through its agents in service, knew or could have known that the said E. D. McCrary was in such physical condition, owing to the want of sleep and rest as to render him unfit to perform the duties of flagman, .... and in requiring the said E. D. McCrary to be and remain in the service of the defendant with scarcely any sleep or rest for such a length of time immediately preceding his death as was completely to exhaust his physical and mental powers, as to render him incapable of properly guarding himself, and the train upon which he was flagging, against the dangers incident to the operation of trains.

The defendants denied the allegation of negligence and wilfulness and interposed the defenses of contributory negligence and assumption of risk. ${ }^{11}$

The jury rendered a verdict in favor of the plaintiff for $\$ 9,500$, and the defendant appealed. On June 25, 1909, the Supreme Court of South Carolina affirmed the judgment of the circuit court.

In the seven cases cited, the courts have decided that the respective accidents were due $(a)$ not to negligence, but in obedience to a law of nature, i.e., in part to the demands of fatigue; (b) to the fact that the injured was overworked to such an extent that sleep, the result of overfatigue, was unavoidable; $(c)$ to the fact that the injured because of fatigue had become dull in apprehension and unmindful of his surroundings; $(d)$ to overexhaustion by reason of protracted employment; $(e)$ as a consequence of the inability of the injured from fatigue and exhaustion to use the requisite skill and care; $(f)$ to the fact that the fatal mistake of the injured was caused by the fatigue of overwork; $(g)$ to the exhaustion of the physical and mental powers of the deceased.

The fact that fatigue has attracted attention to itself as a cause of accidents to the extent that such a conservative body as the judiciary will thus indict it, is noteworthy. The seven

\footnotetext{
" 65 S.E. Reporter, 3.
} 
cases which have been summarized in the preceding paragraphs are not presented because of any legal points involved or for any reasons other than as a sevenfold argument in support of the thesis that fatigue is a cause of accidents.

In the following chapter, all the evidence thus far obtainedchemical, physiological, neural, psychological, industrial (as such), experimental, statistical, legal-will be brought together and offered as a unified whole in defense of the thesis of this investigation. The facts thus collated will be used as a basis for what appears to the writer to be the one best method of reform and of overcoming fatigue as a cause of industrial accidents.

\section{CONCLUSIONS}

In this study it has been found (Section II) that continued work is accompanied by the using up of energy-giving material of the muscles and nerves and by the production and accumulation of toxic fatigue substances. As a result of these processes, muscles respond less and less accurately and the central nervous system becomes less and less efficient in its methods of control. At a certain point in the katabolic processes of the working muscle, inhibitory impulses are sent in to the cortical centers over the afferent nerves. These appear in consciousness in the form of sensations of effort, of strain, of fatigue which constitute warnings and which demand a change in the working mechanism. At the same time, the working muscle gradually becomes weaker, owing to the using up of its energy-giving material, and less responsive, owing to the paralyzing effect of the accumulating toxic substances. If the given activity is continued long enough or if continued for a shorter time with a high degree of unrelaxed tension, the cortical centers submit to katabolic processes and become less accurate in controlling peripheral movements. The combined phases of the fatigue process result in muscular inaccuracy extending from the immeasurably small blockings of the finely adjusted musculature on to the failure to make the grossest muscular contractions.

But the nervous system is so constructed that on occasion it can call out reserve strengths and for short, irregular periods of 
time ward off disastrous fatigue effects. Thus the progressive loss of muscular control accompanying work is marked by irregularly appearing spurts and depressions. Upon these facts the law of fatigue is based which is so generally a fundamental explanation of the cause of accidents. Because knowledge of this law appears to be essential to a thorough understanding of industrial accidents, it is restated here: Uninterrupted work is accompanied by muscular inaccuracy which increases irregularly and at a rate dependent on the rate of activity and on the relative difficulty of the given work for the given individual.

Section III set forth the fact that the increasing muscular inaccuracy which accompanies work is greatly accelerated by the conditions peculiar to industrial conditions-by the monotonous and speeded-up operations, by the mental strain which comes from trying to attend to simple operations maintained at a terrific rate. When these conditions must be met for excessive hours without adequate rest periods, they lead to failure to make even the grossest co-ordinations-to sleep and exhaustion. Since a large proportion, especially of non-fatal injuries, occur in connection with dangerous machinery where a muscular inaccuracy of an inch or of a fraction of an inch results in mutilation of the operative, the facts thus far reviewed may be summarized in the statement that uninterrupted work is accompanied by increasing muscular inaccuracy, which in turn results in increasing chances of accident.

In the series of controlled experiments (Section IV), it was definitely shown that even in a short period of work involving monotony, speed, mental strain, where a high degree of volitional power might be called out for the full time, practically two-thirds of the muscular inaccuracies occurred in the last half of the period. When the rate of work in these experiments was increased and as long as the rate was a "speeded-up" one for the given individual, the number of errors was and remained abnormally increased; moreover, the abnormal increase developed quite generally in the second half of the work periods.

The results of these experiments show that fatigue is an everconstant factor in continued work, that the appearance of this 
constant factor in the foreground during a given work period depends in part on the rapidity of work. These results illuminate the proposition that uninterrupted work is accompanied by muscular inaccuracy which increases at a rate dependent on the rate of activity. When given an industrial interpretation, these results indicate that continued work in the dangerous trades is accompanied during each of the succeeding work periods by increasing chances of accident and at a rate correlative with the speed of work.

The statistics of the hours when accidents occur (Section V) show complex results. As a basis for conclusions work periods were taken when the factors of "warming up" and "final spurt" are eliminated, when a uniform number of people are at work, and when a fairly uniform degree of speed was maintained. Statistics for such work periods show a regularly and pronounced rise in the number of accidents from hour to hour. If extraneous factors are not included statistics of accident-hours indicate clearly that fatigue is a cause of industrial accidents. These statistics make possible a description of typical succession of events: (a) the development of fatigue due to monotonous, speeded-up work under a high pressure of mental strain maintained for long hours at a time; $(b)$ the development of muscular inaccuracies due to this increasing fatigue; $(c)$ increasing numbers of accidents due immediately to this increasing loss of muscular accuracy.

The case against fatigue of overwork is becoming so clear that it is receiving attention in the findings of such a group of men as compose the Interstate Commerce Commission and in the decisions of the conservative courts. Legal authorities have indicted fatigue as a cause of accidents and the related decisions have been presented (Section VI) in further defense of the thesis of this investigation.

In the preceding paragraphs the facts have been summarized upon which the thesis is maintained that fatigue is a cause of industrial accidents. A word of explanation is needed at this point. The accidents which formerly were bulked together and attributed to carelessness now receive a more careful explanation. 
Dr. Emil Roth says that that which is often ascribed to the carelessness ("auf das Konto des Leichtsinns und der Nachlässigkeit") of the worker is in reality the result of oncoming fatigue. ${ }^{1}$ Professor Adams states that this carelessness which has been alleged as a cause of accidents "we are now beginning to realize is often due to the mere stress and strain under which modern factory operatives work." 2 Carelessness is not an ultimate cause, says Elizabeth Butler in her study of Women and the Trades, but a resultant from any one of a multitude of things, one of which is the haste and disregard of personal risk resulting almost inevitably from a piece-work system. ${ }^{3}$

Crystal Eastman, who has made a study of the causes of those fatal accidents which are commonly spoken of as due to the "carelessness of the man injured," says that instead of 95 per cent, only 32 per cent of the fatal accidents can be laid in a measure to the responsibility of the victims; that of this 32 per cent, I I per cent is not due to carelessness, strictly speaking, but to ignorance, youth, and physical weakness; that in the case of the remaining $2 \mathrm{I}$ per cent of the fatalities actually due to carelessness, some of the men were heedless, some inattentive, and some reckless. ${ }^{4}$

For the heedless ones no defense is made. For the inattentive we maintain that human powers of attention, universally limited, are in their case further limited by the conditions under which the work is done-long hours, heat, noise, intense speed. For the reckless ones, we maintain that natural inclination is in their case encouraged and inevitably increased by an occupation involving constant risk; recklessness is part of the trade. Not all accidents due to inattention and recklessness can be thus defended; but speaking generally these two kinds of carelessness cannot fairly be called faults of the workman.

So-called carelessness may be explained by the fact that the fatigued workman is unable to give as close attention to safety appliances and machine guards as a normally resistant workman can give. In their laundry investigation, Clark and Wyatt found

'Emil Roth, 14. Intern. Kong., etc., IV, 290.

'Adams and Summer, Labor Problems (Macmillan, 1908), 483.

${ }^{3}$ Eliz. B. Butler, Women and the Trades (Charities Pub. Com., I909), 108.

4Crystal Eastman, Work Accidents and the Law (Charities Pub. Com., 19ro), 95. 
that "each burn is due to carelessness," but that if the girls were to be careful, they would have to focus their minds on selfprotection, instead of on the proper accomplishment of their tasks, and would also have to work at a lower rate of speed. ${ }^{5}$ Hence it is becoming evident that accidents which have been hastily and unscientifically classed as due to "negligence" or to "carelessness" are in reality due to the inexorable demands of the overworked human organism.

In concluding this summary, it may be added that as soon as it becomes evident that fatigue is a cause of accidents and as soon as the way in which fatigue causes accidents becomes clear, definite methods of prevention must be determined upon and put into operation. [Society cannot afford to allow its industrial members to submit themselves unduly to the law of fatigue underlying accidents or to be coerced by external conditions in a similar fashion. Society cannot afford to permit wage-earners because of the fatigue effects of long hours of monotonous, speeded-up toil to be destroyed or even to be removed temporarily or permanently as means of support to large families (and the support of these families thus to be thrown upon the public).

The deaths and disablements due to fatigue represent a needless waste to society. Louis M. Greeley says that every day the enormous waste to society from industrial accidents becomes clearer, that the burden imposed upon public charity becomes heavier, and that the conviction becomes stronger that our present inaction in these matters must give place to intelligent action in order that these great evils be lessened. ${ }^{6}$

At this point, the question logically follows: What can be done to reduce the fatigue which causes accidents? ${ }^{7}$ The answer must be psychological and economic. Make it overwhelmingly to the financial advantage of employers to reduce to the narrowest limits the number of accidents that befall their 404.

s Clark and Wyatt, "Women Laundry Workers in New York," McClure's, XXXVI,

'L. M. Greeley, "Changing Attitude of the Courts toward Social Legislation," Survey, XXIV, 778.

'It will be clear that the defense of the thesis of this investigation does not in itself call for an elaborate discussion of measures for prevention. Consequently, the suggestions made here will be presented only in outline form. 
employees. $^{8}$ The chief way to prevent fatigue-accidents effectively is to make the lives and limbs of his employees as important to an employer as the output. ${ }^{9}$ The all-important measure in minimizing fatigue-accidents appears to be compulsory accident-insurance (constitutionality granted, of course). ${ }^{10}$ This method of prevention works better than any other in Germany, and is described briefly by Professor Henderson:

The German industrial-insurance law requires the employers to pay onethird of the cost of sickness-insurance, and all the premiums for accidentinsurance; the sickness-insurance fund cares for the disabled workman for thirteen weeks, after which the employers' fund pays for further support during disablement due to accident. Naturally, it is seen to be to the interest of all parties to reduce the number of accidents to the lowest possible level by taking all precautions suggested by experience. If a workingman is careless he may be fined and thus disciplined to observance of the regulations made for his benefit. If a certain factory shows a high rate of injury to employees, its assessment is correspondingly raised by the executive committee. The accident-insurance law works automatically to reduce accidents. ${ }^{11}$

(a) It is safe to say that when it becomes financially advantageous to employers to minimize danger of accident to employees they will replace monotonous and speeded-up handoperations as far as possible by automatic processes. Piece-work in connection with dangerous machines will be supplanted by time-work. Miss Anderson, chief lady inspector in England, says that by cutting down piece-work the danger of accidents will be lessened. In laundries more than one manageress has been able to minimize the risk of accident by insisting on payment by time, not by piece. ${ }^{12}$ It follows from the law of fatigue (Sec-

${ }^{3} \mathrm{H}$. R. Seager, Industrial Insurance (Macmillan, 1910), 28.

- Crystal Eastman, op. cit., ro6.

${ }^{10}$ A problem for investigation arises at this point: What effect has compulsory accidentinsurance in Germany had upon the number of accidents per year per thousand? Adequate data are not at hand whereby a definite answer can be given. The situation is exceedingly complex and many factors would have to be given consideration, some of which may be indicated. (r) Year after year employees are speeded up in order to secure an increasing outputand a higher accident rate would naturally result from higher rates of speed. (2) During the industrial development of a country, untrained and inexperienced workmen are constantly being added to the force - a fact which would tend to increase the accident rate. (3) Stricter control is exercised now than twenty-five or even ten years ago in reporting accidents. Many other factors might be mentioned.

${ }^{12}$ C. R. Henderson, "Wood-Workers and Their Dangers," World To-Day, XXXVI, 976.

"A. M. Anderson, Sess. Papers (House of Lords, 1904), LIX, 201. 
tion II), and from the results of the experiments (Section IV), that a reduction in speed would mean a reduction in chances of accident.

But in many industries a reduction in speed is hardly practicable-competition and economic demands are too strong. To reduce speed would seem a retrogression in industry. Where it is impossible to substitute automatic machines, the employer whose employees have been made as valuable to him as his output (by compulsory accident-insurance) will lessen the dangers of speed by shortening hours of work. ${ }^{13}$

(b) Under compulsory accident-insurance laws the employer would lessen the danger of accidents by making hours of continuous work commensurate with the intensity and danger of the work. Crystal Eastman says that shorter hours-an eight-hour day for all railroaders-is about the most important thing to reduce the number of accidents. ${ }^{14}$ In regard to the employees in the dangerous wire-mills, Miss Eastman says that one way to lessen danger of accident will be "to reduce the hours and shorten the shift."15

Greater intensity of work necessitates longer periods of relaxation. If the strain of the work cannot be lessened, the duration must be. Think of the crane man (in the steel-mill) upon whose alertness and care depend the lives of several others. His is a hot, unpleasant, lonely job. There is no one to spell him. He cannot get down from his cab for any reason. And he works twelve hours every day in the year except Christmas and the Fourth of July. No steel company can maintain that it has done everything to prevent accidents until it has reduced the working hours of men in such responsible positions. ${ }^{10}$

(c) Men and women must not be allowed to work at speeded and dangerous machines according to personal ambition but according to the physical ability of the given individuals. This norm will be attained not by the methods of the ordinary factory inspector nor even by medical factory inspection, but ultimately by examinations including tests possibly similar to those described in Section IV in which each individual receives expert attention. The physically unfit for the more dangerous forms of work must be weeded out by expert tests; they must not be allowed as now

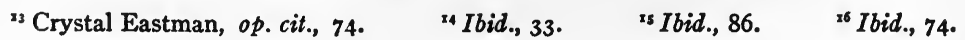


to assume the more dangerous forms of work from economic motives and be eliminated by the painful and costly method of accident; for here as elsewhere the law of the survival of the fittest holds. The physical ability (and mental alertness) of the worker and the hours of work must be proportional to the fatiguing character and danger of the work.

(d) Compulsory accident-insurance so regulated that the employee must contribute a certain percentage of the fund from which compensations are paid will enlist the strong forces of labor itself, from individual laborers as such, to the powerful labor unions, in a more successful fight against fatigue and other causes of accidents. When it is made to the financial advantage of both employee and employer to reduce accidents, safety appliances, for example, will be not only installed, but actually used. Employers and employees must use various methods of instructing new and uninitiated workers as to the subtle dangers of fatigue. "Ignorance permits accidents which might be prevented."17. The potential force of the labor union under rational control, as a means of securing education of employees in industrial hygiene, of securing shorter hours and more adequate rest periods, etc., would be aroused to activity if it were made to the financial advantage of the union to do so. The union, made up of the workers themselves, is always present to observe violations, which cannot be the case, for instance, with factory inspectors.

While a discussion of methods for prevention of fatigue as a cause of accidents does not properly belong here, it is maintained that a method worthy of consideration is compulsory accidentinsurance-granted the constitutionality of such a procedure, of course. In other words, it is contended that in the prevention of fatigue as a cause of accidents, the will of the employer is preeminently important, and the will of the employees expressed through labor unions under rational control is of next importance.

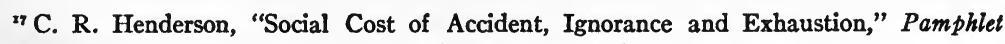
No. 72, National Child Labor Commission (New York, r9o8). 
an a

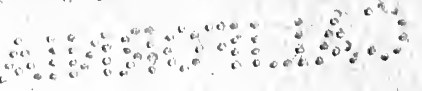





\section{DAY USE}

RETURN TO DESK FROM WHICH BORROWED LOAN DEPT.

This book is due on the last date stamped below, or on the date to which renewed.

Renewed books are subject to immediate recall.

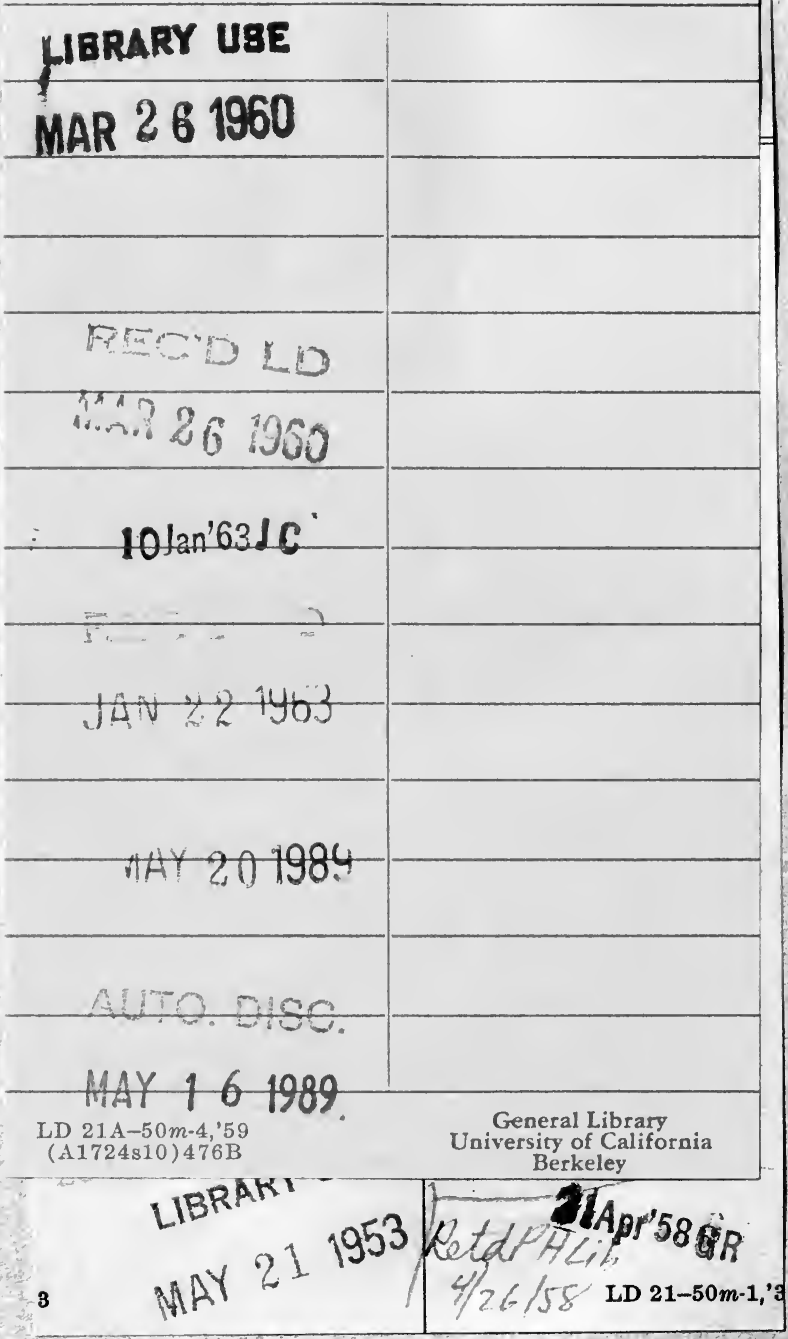




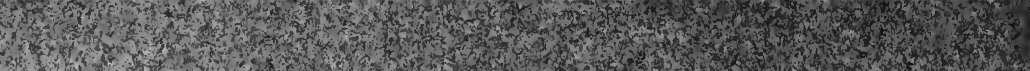

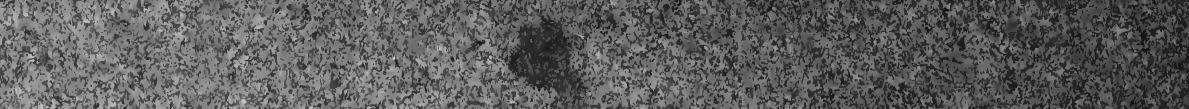

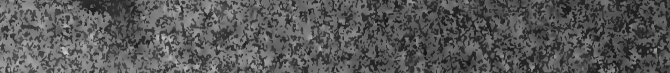

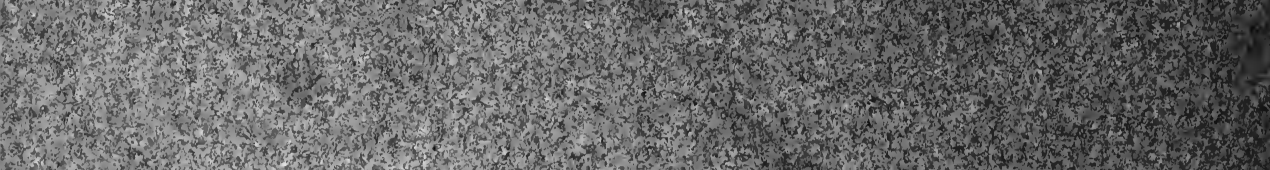
3
7

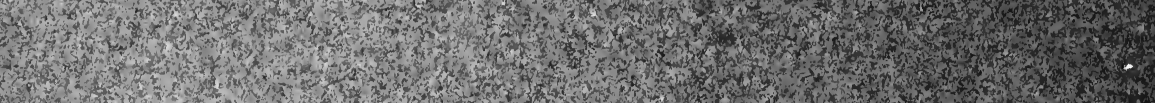

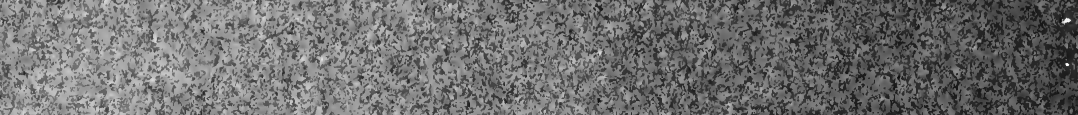

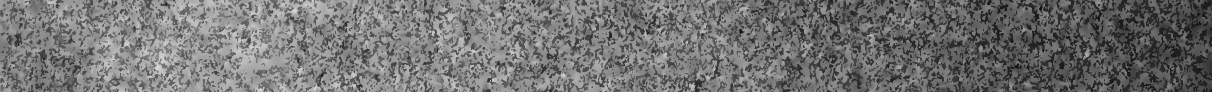

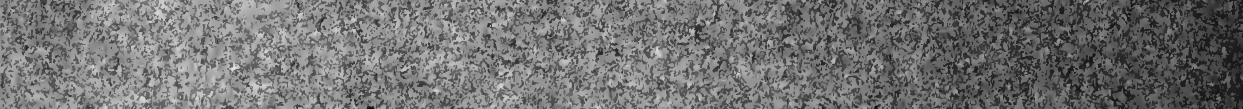

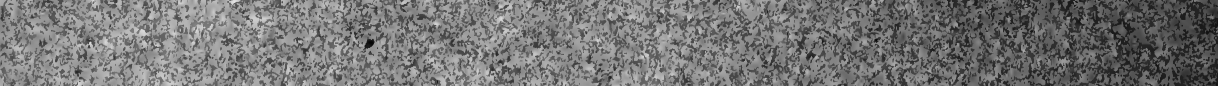
13.

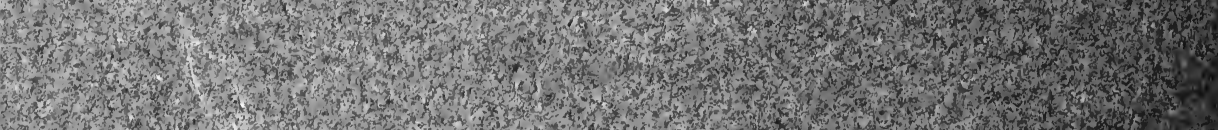

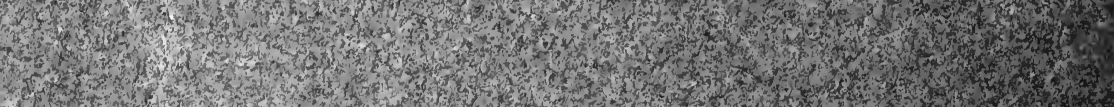

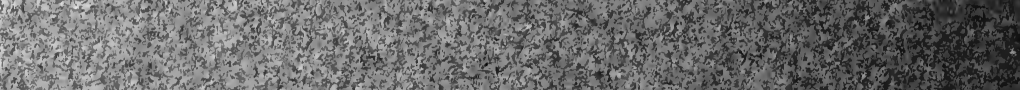
How $x$.

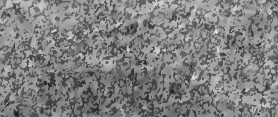

(2):

-3.

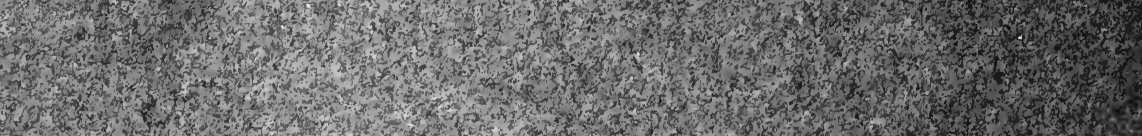

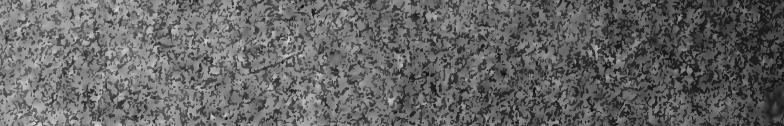

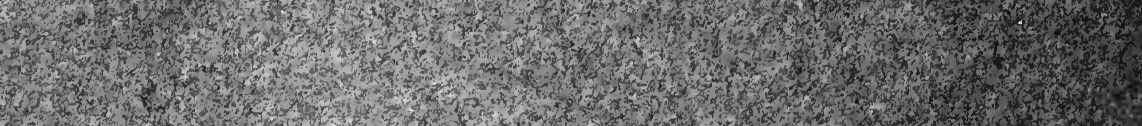

-

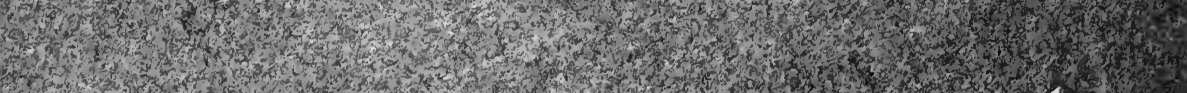
1.

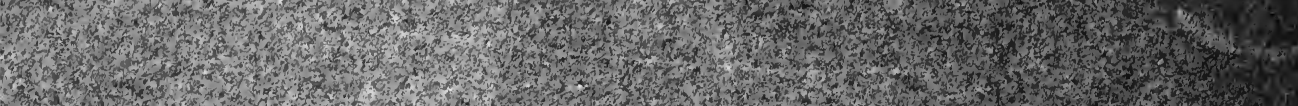

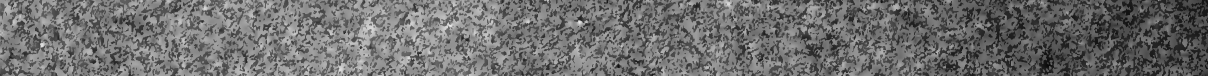

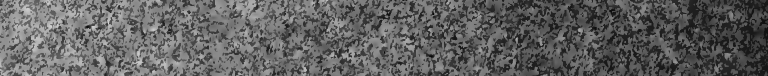

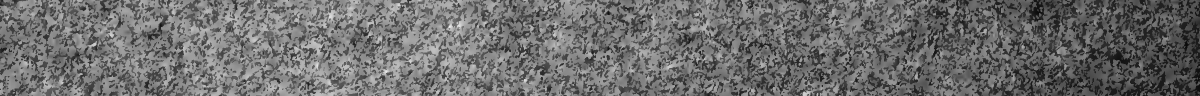

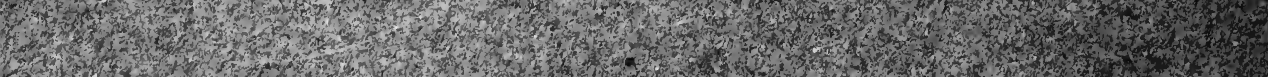

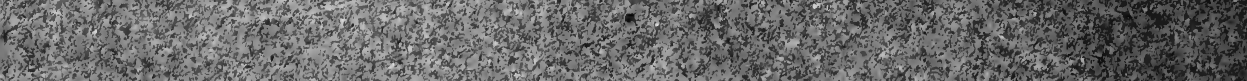
S. 2.

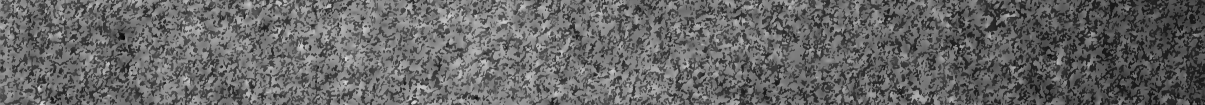

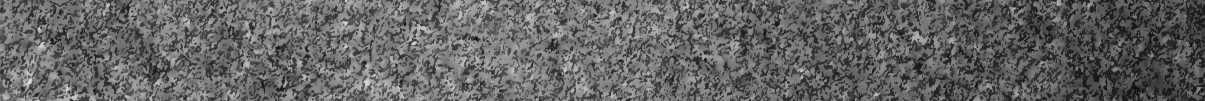

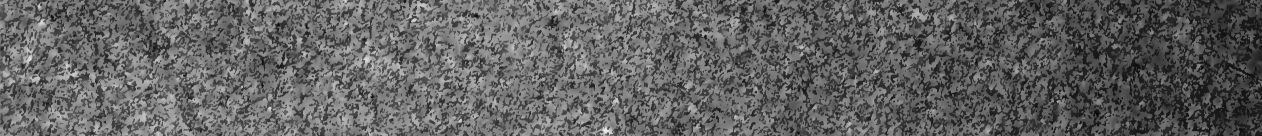

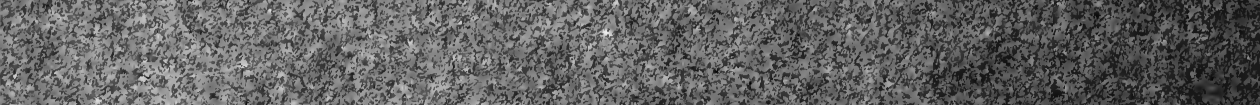

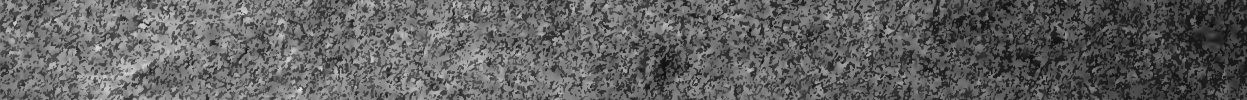
Not 